\title{
The effect of gas phase polydimethylsiloxane surface treatment of metallic aluminum particles: Surface characterization and flow behavior
}

\author{
Bellamarie Ludwig ${ }^{\mathrm{a}, *}$, Jennifer L. Gray ${ }^{\mathrm{b}}$ \\ ${ }^{a}$ Applied Research Laboratory, The Pennsylvania State University, North Atherton Street, State College, PA \\ 16801,USA \\ ${ }^{b}$ Materials Research Institute, The Pennsylvania State University, USA \\ *Corresponding author. Tel: (814)865-8047; E-mail: bxb234@psu.edu (B. Ludwig); jlg375@psu.edu (J.L. Gray)
}

\begin{abstract}
Aluminum particles were exposed to gaseous polydimethylsiloxane (PDMS) to produce a hydrophobic surface coating for enhanced flow and fluidity. Surface retention of the intact PDMS was confirmed through infrared and X-ray photoelectron spectroscopy. Transmission electron microscopy was used to image cross-sections of the treated particles and energy dispersive spectroscopy element maps demonstrated the presence of a surface layer consisting of silicon and oxygen. Density measurements provided evidence for improvements in the Hausner ratio and Carr index of the PDMS-treated aluminum, indicating a reduction in inter-particulate cohesion through increased bulk density. Stability, compressibility, shear, aeration, and permeability of the particles were assessed by powder rheometer. The compressibility was reduced by approximately $32 \%$ following surface treatment, revealing a reduction in void space, while Mohr's circle analysis and shear testing determined that the extrapolated cohesion value was reduced by approximately 53\% and the flow factor at $6 \mathrm{kPa}$ was doubled. Aeration testing showed that the air velocity required to obtain a fluidized bed was on the order of $0.35 \mathrm{~mm} / \mathrm{s}$ for the treated powder, whereas the raw powder could not be uniformly fluidized. PDMS may be a viable option for the large-scale treatment of aluminum powder for flow applications.
\end{abstract}

Keywords: Aluminum powder; Polydimethylsiloxane; X-ray photoelectron spectroscopy; Diffuse reflectance infrared Fourier transform spectroscopy; Flowability; FT4 powder rheometer

\section{Introduction}

Metallic aluminum powders are widely used as propellants, pigments, and fillers to impart enhanced mechanical and thermal properties (Bishay, Abd-El-Messieh, \& Mansour, 2011; Mamunya, Davydenko, Pissis, \& Lebedev, 2002). These applications take advantage of the metallic properties of aluminum, although the presence of the typical passivated surface layer can cause complications with regard to stability, compatibility, and dry powder flow. Most metals form a passivated oxide layer during exposure to ambient 
oxygen (Hunter \& Fowle, 1956) and subsequent hydration of this layer can generate surface hydroxyl groups (Diggle \& Ashok, 1976). These surface groups can be used as reactive sites to covalently attach surface coatings that improve the compatibility of the metal with other materials or introduce new properties. This technique is widely used in the pigment industry through employing polymeric coatings to enhance the dispersion of metal powders in paints and plastics (Karlsson, Palmqvist, \& Holmberg, 2006), provide corrosion protection (Montemor, 2014; Stratmann, Feser, \& Leng, 1994), and increase colloid stabilization in organic media (Kuchibhatla, Karakoti, \& Seal, 2005; Dobias, Qiu, \& von Rybinski, 1999), all of which are predominantly liquid-phase applications. In some cases involving powder handling, however, a dry product is desired, such as during the delivery of bulk fillers and propellant powders. The associated flow behavior, a direct consequence of the powder surface properties, therefore becomes an important parameter in the design of off-loading equipment.

The flow behavior of powders is difficult to characterize because powders can behave differently depending on the discharge method, container materials, and method of fluidization. Powders that are considered free flowing in one application may exhibit poor flow under a different set of conditions. In gas fluidized applications, for example, stable delivery is dependent on the aeration and permeability properties of the powder. Generally, cohesive powders tend to have erratic flow in fluidizing environments because of the void volumes produced from air pressure differentials throughout the powder bed. These void spaces are also formed through particle-particle surface contacts or inter-particulate cohesion, which is common in fine powders where the effects of attractive forces between particles are greater than gravitational forces. Achieving reliable and consistent flow with fine powders can be challenges, although surface treatments can be used to reduce inter-particulate cohesion. As noted, metallic aluminum powders have surface reactive sites that make surface treatment an attractive option for improving the dry powder flow properties.

Hydrophobic alkoxysilane-based coatings produced through bulk solution depositions have been shown to enhance the flow and fluidization properties of metallic aluminum powders (Ludwig \& Miller, 2015). Alkoxysilanes having more than one hydrolysable group have also been found to form oligomers and extended polymer networks in solution (Brochier Salon \& Belgacem, 2010) because these multiple functional groups can react with one another, producing numerous short chain polymers that may subsequently react with the substrate surface. These cross-linked polymers are analogous to polysiloxanes or, more generically, silicones. Silicones have widespread commercial use in the pharmaceutical, food, and lubricant industries because they exhibit low reactivity and are non-toxic. They are produced in massive quantities each year and thus are ideal for large-scale operations. Polydimethylsiloxane (PDMS) is an example of a hydrophobic siloxane-based polymer. It is a liquid at room temperature and has the generic structure $\left(\mathrm{CH}_{3}\right) \mathrm{SiO}\left[\left(\mathrm{CH}_{3}\right)_{2} \mathrm{SiO}\right]_{n} \mathrm{Si}(\mathrm{CH})_{3}$, where $n$ can range from 0 to 5000. Despite the relatively low vapor pressure of this polymer, a processing temperature in the vicinity of $250{ }^{\circ} \mathrm{C}$ has been shown to deposit thin layers of PDMS on silica and copper 
powders (Kim et al., 2012; Park, Sim, Jeong, Seo, \& Kim, 2012; Yuan et al., 2008). Previous applications of PDMS have used the polymer for coating purposes for its protective and electronic properties, whereas the work described herein employed PDMS for its hydrophobicity. This study was predicated on the theory that PDMS-treated aluminum particles would exhibit reduced cohesiveness, resulting in increased bulk density, enhanced flow behavior, and improved fluidity relative to untreated aluminum powder.

Typical alkoxysilane treatments are performed in bulk slurries, and these processes require special considerations with regard to handling the solvent because post-processing removal of the solvent can extend the processing time significantly. For this reason, the present work used a gas-phase method to reduce solvent waste and circumvent the technical challenges associated with solvents. The work presented in this paper is thought to provide valuable insights into the chemical properties and flow behavior resulting from a PDMS surface layer on fine aluminum particles.

\section{Materials and methods}

\subsection{PDMS surface treatment}

PDMS with terminal hydroxyl groups ( $M_{n}$ approximately 550, viscosity approximately $25 \mathrm{cSt}$; Aldrich, USA) and metallic aluminum powder ( $d_{50}$ approximately $20 \mu \mathrm{m}$, Lot No. 12-3008; Valimet, USA) were used as received. Ultra-high purity nitrogen was employed as the fluidizing gas in conjunction with an inline oxygen/hydrocarbon trap and flow controller. A simple gas-phase deposition apparatus was fabricated in house using two porous gas distributor plates, a glass cylinder with a heating jacket, and a nitrogen gas flow line (flow velocity $=0.2 \mathrm{~mm} / \mathrm{s}$ ) connected to a PDMS reservoir. Prior to each deposition trial, aluminum powder (300 g) was loaded into the cylinder and fluidized, to improve the particle-gas-phase interactions. While in the apparatus, the powder was periodically agitated/homogenized. The powder was heated to and held at approximately $100^{\circ} \mathrm{C}$ for $1 \mathrm{~h}$ prior to treatment to remove physisorbed water and also maintained at this same temperature for the duration of the deposition process. The PDMS was heated to approximately $250{ }^{\circ} \mathrm{C}$ and the resulting vapors were mixed with the nitrogen gas stream over a period of approximately $4 \mathrm{~h}$. A schematic of the deposition apparatus is shown in Fig. 1.

Fig. 1

\subsection{Materials characterization}

Diffuse reflectance Fourier transform infrared spectroscopy (DRIFTS) data were collected using a Fourier transform infrared spectrophotometer (Vertex V70, Bruker, Germany) equipped with a mercury-cadmiumtelluride detector. Spectra were collected with a Praying Mantis ${ }^{\mathrm{TM}}$ diffuse reflectance accessory (Harrick, 
USA) equipped with $\mathrm{CaF}_{2}$ windows with a $900-\mathrm{cm}^{-1}$ cutoff. The reactor was purged with argon continuously through all measurements. The spectrum resolution was set to $6 \mathrm{~cm}^{-1}$ and 400 scans were performed. Powdered potassium bromide $(\mathrm{KBr})$ was used to acquire a reference spectrum and was dried to $350{ }^{\circ} \mathrm{C}$ for 30 min prior to use. Additional $\mathrm{KBr}$ spectra were collected to enable subtraction of atmospheric water contributions.

X-ray photoelectron spectroscopy (XPS) was performed using a Kratos Axis Ultra instrument (Shimadzu, Japan) with a monochromatic Al K $\alpha$ X-ray source. Powdered samples were mounted on a silicon substrate using a double-sided tape $\left(3 \mathrm{M}^{\circledR}\right)$. Analysis was performed at a constant system pressure of $10^{-8}$ torr, employing a pass energy of $80 \mathrm{eV}$ for the survey scans with a step size of $0.5 \mathrm{eV}$. High-resolution data were collected at $20 \mathrm{eV}$ with a step size of $0.1 \mathrm{eV}$. Charge correction was employed using the $\mathrm{C} 1 \mathrm{~s}$ peak at $284.8 \mathrm{eV}$ as an internal standard.

Particles were imaged using environmental scanning electron microscopy (ESEM, Hitachi S300N, Japan) with a tungsten filament and $10 \mathrm{~nm}$ resolution. An Everhart-Thornley detector was employed to collect the secondary electron images. Samples were prepared by attaching a double-sided carbon tape on a standard scanning electron microscopy (SEM) stub and applying a small amount of powder $(<5 \mathrm{mg})$ onto the tape surface, followed by dislodging any loose powder by tapping the stub. All powders were analyzed in high vacuum mode.

The particle size distributions (PSDs) of specimens on a volume basis were examined using laser diffraction (Mastersizer, Malvern Instruments, UK). Aluminum powder samples were dispersed in isopropyl alcohol at a concentration of approximately $500 \mathrm{mg} / 5 \mathrm{~mL}$ and sonicated for $1 \mathrm{~min}$ prior to analysis. These dispersions were subsequently transferred into a wet sample dispersion unit until an obscuration value in the range of 10\%-20\% was obtained, after which sizing data were acquired using 10000 sweeps. All measurements were conducted in triplicate and the average is reported for each sample.

Cross-sectional transmission electron microscopy (TEM) samples were prepared using an FEI Helios NanoLab 660 DualBeam focused ion beam (FIB; FEI, USA) in conjunction with the in situ lift-out technique. A representative particle was chosen that was approximately $6 \mu \mathrm{m}$ in diameter with a relatively smooth surface as determined by SEM. Using the FIB, a layer of carbon was first deposited over the surface of the particle to prevent damage during the subsequent $\mathrm{Ga}^{+}$ion beam milling. A thin section was milled from the center of the particle, spanning the entire diameter, and then attached to a TEM grid. Following this, the sample was further thinned with the ion beam to a final thickness of approximately $100 \mathrm{~nm}$.

Scanning transmission electron microscopy (STEM) was performed using an FEI Talos TEM at an accelerating voltage of $200 \mathrm{kV}$. High-angle annular dark field (HAADF)-STEM images(showing primarily 
mass contrast approximately proportional to the square of the atomic number of the elements present) were collected at the edges of sample particles. Energy dispersive spectroscopy (EDS) maps were simultaneously collected to determine the elements present at the edges of the particles, using Bruker SuperX quad X-ray detectors. Elemental mapping was performed over the span of $5 \mathrm{~min}$ with a STEM beam current of approximately $0.25 \mathrm{nA}$. This was possible owing to the high X-ray count rates that could be achieved with the SuperX detector system combined with the high brightness X-FEG (extreme field emission gun) electron source of the Talos. Standardless Cliff-Lorimer quantification was performed on the de-convoluted EDS line intensity profiles across the surface of the particle to show the compositional variation at the edge.

\subsection{Bulk property analysis}

Powder density measurements for calculation of the Hausner ratio $\left(H_{\mathrm{R}}\right)$ were performed according to the ASTM B527-06 standard, using an Autotap instrument (Quantachrome, USA). As called for in the ASTM standard, $100 \mathrm{~g}$ of powder were loaded into a $100-\mathrm{mL}$ borosilicate graduated cylinder and the instrument had a drop height of $3.2 \mathrm{~mm}$ and a tap rate of $260 \mathrm{taps} / \mathrm{min}$. The tapped density was measured until there was no further change, which occurred after approximately 3000 taps. The density measurements were performed in triplicate and the average values, together with standard deviations, are reported. The $H_{\mathrm{R}}$ values were calculated according to the Eq. (1):

$$
H_{\mathrm{R}}=\rho_{\mathrm{T}} / \rho_{\mathrm{A}}
$$

where $\rho_{\mathrm{T}}$ is the tapped density and $\rho_{\mathrm{A}}$ is the apparent density. Hausner ratios greater than 1.4 are considered to represent a cohesive material (designated as $\mathrm{C}$ ), while values in the range of 1.4-1.25 and less than 1.25 correspond to transition group (A-C), and aeratable (A) materials, respectively (Hausner, 1967). The Carr index is another powder flow indicator based on density calculations and is described by the Eq. (2):

$$
C I=\left(\rho_{T}-\rho_{A}\right) / \rho_{T} * 100 .
$$

A powder with a Carr index less than $10 \%$ is considered to have excellent flow, while values of 10-15, 15-20, 20-25, 25-30, and greater than 30\% indicate good, fair, passable, poor, and very poor flowability, respectively (Carr, 1965).

A Freeman FT4 powder rheometer (Freeman Technologies, UK) was used to measure various flow and fluidization properties of both raw and treated powders. A thorough description of the instrument, including shear, compressibility, permeability, aeration, and stability measurements has been presented elsewhere (Freeman, Freeman, \& Armstrong, 2011; Freeman, 2007), and thus only a short description is included here. For stability, variable flow rate, and aeration measurements, a blade $(23.5 \mathrm{~mm})$ descends into the sample vessel 
(25-mm diameter, 25-mL capacity, borosilicate glass) containing the powder. The blade moves with a speed of $100 \mathrm{~mm} / \mathrm{s}$ and $\mathrm{a}-5^{\circ}$ helix angle unless stated otherwise. Measurements of the torque and force curves generated by the instrument as a function of powder bed height are made and values reported are in terms of energy $(\mathrm{mJ})$. There are generally one to two conditioning cycles $\left(100 \mathrm{~mm} / \mathrm{s}\right.$ tip speed, $\left.-5^{\circ}\right)$ run prior to a test cycle to remove any effects of sample loading variability from the results. For most tests, the vessel is split after conditioning to produce a consistent volume for each measurement.

The energy measured on the descent of the blade is considered to represent the basic flowability energy (BFE) of the test material, while the energy expenditure upon ascent is the specific energy (SE). These two values are different because, during descent, the bed is restricted by the bottom of the vessel, whereas during ascent the bed is unrestricted. While the blade is ascending, the main effect on the resulting measured energy is that of gravity, thus the result is reported in terms of mass. The stability and variable flow rate tests probe the manner in which the powder responds to additional conditioning cycles and determine whether or not the flow energy values change as a result of several conditioning cycles. Seven tests are completed at a tip speed of 100 $\mathrm{mm} / \mathrm{s}$ to quantify changes in total energy after each conditioning cycle. The ratio of the total energy measured in the last conditioning cycle to the initial value is termed the stability index (SI) and is described by the Eq. (3):

$$
S I_{n}=\frac{B F E_{\text {post } n \text {th cycle }}}{B F E_{\text {inital }}}
$$

The second part of this test employs decreasing tip speeds $(70,40$, and $10 \mathrm{~mm} / \mathrm{s})$ to investigate the effect of forced flow changes on the total energy value. This is quantified by determining the ratio of the total energy at the lowest tip speed $(10 \mathrm{~mm} / \mathrm{s})$ to the total energy at the highest tip speed $(100 \mathrm{~mm} / \mathrm{s})$, as given by the flow rate index (FRI) in the Eq. (4):

$$
F R I=F E_{10 \mathrm{~mm} / \mathrm{s}} / F E_{100 \mathrm{~mm} / \mathrm{s}} .
$$

As noted above, the SE value is determined during the stability and variable flow rate tests. This value is reported in terms of energy per gram of material $(\mathrm{mJ} / \mathrm{g})$ and, in general, a higher specific energy implies a more cohesive poorly flowing powder.

A full description of Mohr circle analysis can be found in various powder analysis textbooks (Schulze, 2008) as well as in the literature (Masuda, Higashitani, \& Yoshida, 2006). In the present work, after conditioning and splitting, the powder was compacted by a vented piston to a pre-shear stress value of $6 \mathrm{kPa}$. This value was selected based on estimated application-based consolidation stress and density values, as reported by Schulze (2008). The vented piston allowed for the uniform escape of entrained air within the 
powder. A shear head was used to measure the incipient failure at a given applied normal stress; these points are referred to as the yield loci. Yield loci were collected at increasing applied normal stress values (2.0-4.0 $\mathrm{kPa}$ in $0.5-\mathrm{kPa}$ increments) to indicate the shear stress observed at the point of plastic deformation of the powder bed. Linear regressions were used to extrapolate the cohesion value based on the Eq. (5):

$$
\tau_{\mathrm{f}}=c+\sigma \tan \phi
$$

where $\tau_{\mathrm{f}}$ is the shear stress, $c$ is the cohesion, $\sigma$ is the normal stress on the failure plane, and $\phi$ is the angle of internal friction. The unconfined yield strength (UYS) and the major principal stress (MPS) are derived from the minor and major Mohr circles, respectively, and their intersections with the $\mathrm{x}$-axis. These values were used to determine the flow factor at $6 \mathrm{kPa}$ based on the Eq. (6):

$$
f f_{\mathrm{c}}=\sigma_{1} / \sigma_{\mathrm{c}}
$$

where $\sigma_{1}$ is the MPS and $\sigma_{\mathrm{c}}$ is the UYS.

Compressibility measurements were performed at consolidating pressures ranging from 0.5 to $8 \mathrm{kPa}$, using a vented piston after initial conditioning cycles and splitting. Generally, more cohesive powders contain a greater amount of entrained air as a result of poor packing caused by agglomerates. A consistent sample mass was used to eliminate direct mass effects as well as to improve reproducibility. The change in sample height resulting from each test is reported as a percentage.

In this work, aeration testing was used to evaluate powder fluidizability as a result of air flowing through the powder bed, using a porous distributor at the bottom of the vessel. This process mimics a fluidized bed environment and allows the flow energy to be calculated at various air velocity speeds. An air velocity range of $0.15-0.60 \mathrm{~mm} / \mathrm{s}$ was employed, in $0.05-\mathrm{mm} / \mathrm{s}$ increments. The flow energy was measured using the standard blade accessory.

Permeability data were collected after the bed had been conditioned and split as described earlier. The vented piston consolidated the powder at increasing normal stresses (1-8 $\mathrm{kPa}$ ) and the pressure drop was measured for each applied normal stress. This pressure drop was used to determine the permeability $\left(\mathrm{cm}^{2}\right)$, applying Darcy's law as in the Eq. (7) (Darcy, 1856):

$$
k=\frac{q \mu L}{\Delta P},
$$


where $k$ is the permeability $\left(\mathrm{cm}^{2}\right), q$ is the air velocity $(\mathrm{cm} / \mathrm{s}), \Delta P$ is the pressure drop (mbar), $\mu$ is the air viscosity (mbar/s), and $L$ is the height of the powder column $(\mathrm{cm})$. This test allows a qualitative assessment of changes in air flow with increasing bulk density arising from the consolidation stress.

All measurements were performed in triplicate and error bars representing plus and minus one standard deviation are included on figures, while the numerical error ranges are included in tables where appropriate.

\section{Results and discussion}

\subsection{Particle size, morphological, and surface chemical characterizations}

PSD is known to have a significant impact on flow properties, and spherical particles generally have the best flow properties because they have fewer possible interconnections. The powders selected for this study were spherical gas-atomized aluminum particles with a $d_{50}$ of approximately $20 \mu \mathrm{m}$ and their PSDs were measured by dynamic light scattering, as shown in Fig. 2. It is evident that there were no appreciable changes in the PSDs of the powders, suggesting that any flow enhancement following surface treatment was not related to changes in particle sizes.

Fig. 2

Particle shape can also affect flow properties, as irregular or nodular powders have morphological abnormalities that can restrict movement as a result of particle-particle interlocking and physical contact. The SEM image presented in Fig. 3 shows the spherical shapes and smooth surfaces associated with the gasatomized particles. It can also be seen that small "satellite" particles are attached to the surfaces of the larger particles, which is typical of gas-atomized materials (Lawley, 1992). Qualitatively, this image also indicates that the PSD of these aluminum particles is broad, a factor that, theoretically at least, should contribute to better flow. The fine size of these particles, however, could lead to cohesion issues, which necessitates surface treatment.

Fig. 3

In practice, alkoxysilanes are hydrolyzed to create hydroxyl groups that can associate with oxide surfaces and can subsequently be cured in a condensation-type reaction to form surface ester linkages (Kurth \& Bein, 1992). The PDMS used in this work had terminal hydroxyls and was similar to an alkoxysilane oligomer or extended polymer, and therefore was anticipated to react with or be physisorbed onto the surface of the aluminum particles, in a manner similar to an alkoxysilane. To assess the extent to which this occurred, 
surface-sensitive techniques were used to identify the components remaining on the aluminum surfaces after exposure to volatized PDMS.

XPS survey and high-resolution spectra of the raw and treated powders were used to study the surface chemical composition and chemical environments of the elements present before and after PDMS treatment. In the case of the untreated aluminum powder, the high-resolution aluminum $2 \mathrm{p}$ peak was split into two different binding energy (BE) values for metallic and oxidized aluminum at 71.6 and $74.3 \mathrm{eV}$, respectively. The high resolution oxygen $1 \mathrm{~s}$ peak obtained from the raw powder was also split into two different BE values, for O-Al and $\mathrm{O}-\mathrm{C}$ at 531.6 and $530.5 \mathrm{eV}$, respectively. The presence of $\mathrm{O}-\mathrm{C}$ groups on the surface was corroborated by the carbonate content evident from the carbon 1s spectrum. Fig. 4(a) provides the XPS survey spectra for the raw and PDMS-treated powders. Both silicon $1 \mathrm{~s}$ and $2 \mathrm{p}$ peaks are prominent in the spectrum of the treated sample, but are not detectable in the raw sample spectrum, indicating the presence of a silicon-based material on the surfaces of the treated particles within the depth of approximately $10 \mathrm{~nm}$ to which data were obtained. Fig. 4(b) presents the high-resolution spectrum of the silicon 2p peak at a BE of $101.9 \mathrm{eV}$ and is in close agreement with the reference value reported for PDMS (Moulder, Stickle, Sobol, \& Bomben, 1993). The carbon 1s peak shows three apparent maxima at 284.8, 286.1, and $289.7 \mathrm{eV}$, corresponding to aliphatic, carbonyl, and carbonate types of carbon on the surfaces of the raw powder (Moulder et al., 1993). The treated powder spectrum has maxima at 284.7, 286.7, and $298.4 \mathrm{eV}$ for the same types of carbon, (Fig. 4(c)), although the carbonyl and carbonate peak intensities were decreased after treatment, as demonstrated by the data in Table 1. All peak values obtained for the PDMS-treated powder were in close agreement with experimental values reported for neat PDMS (Moulder et al., 1993), suggesting little disruption of the siloxane backbones as a result of heating and gas flow.

Fig. 4 \& Table 1

Fig. 5 shows the DRIFTS spectra obtained from the raw and PDMS-treated aluminum powders. PDMS contains methyl groups that absorb in form of both deformation and stretching of individual $-\mathrm{CH}$ bonds. The spectrum of PDMS-treated aluminum powder exhibits an absorbance peak at approximately $1260 \mathrm{~cm}^{-1}$ that is associated with the $-\mathrm{CH}_{3}$ deformation or umbrella mode. In addition, the broad absorbance centered around $1100 \mathrm{~cm}^{-1}$ corresponds to the $\mathrm{Si}-\mathrm{O}-\mathrm{Si}$ stretching mode, and suggests that the deposition process and associated heating did not decompose the Si-O-Si backbone within the PDMS structure (Romanenko \& Tkachuk, 1973). Owing to the use of $\mathrm{CaF}_{2}$ windows, the wavenumber cutoff in these spectra was approximately $900 \mathrm{~cm}^{-1}$, although a broad Al-O deformation peak is observed in the vicinity of this cutoff value, centered at $950 \mathrm{~cm}^{-1}$ (Morterra \& Magnacca, 1996). All the peaks in these spectra are consistent with the deposition of a siloxanelike layer on the aluminum particle surfaces.

Fig. 5 
Hydrogen bonding between the PDMS - OH groups and the aluminum oxide layer was difficult to ascertain via the techniques employed in this work. The aluminum powder being examined had a low surface area, which limited the intensity of the infrared absorbance modes. Thus, although no appreciable hydrogen bonding peaks were observed, they may simply have been present at intensities below the level of detection. As well, the $\mathrm{Si}-\mathrm{OH}$ vibrational modes of hydrogen bond silanols are typically found in the $3400-3200 \mathrm{~cm}^{-1}$ region (Smith, 1960), which also includes strong absorbance peaks owing to molecular water (Al-Abadleh \& Grassian, 2003). Although dried $\mathrm{KBr}$ was used, atmospheric moisture and residual adsorbed molecular water could have led to misleading results in this region. The presence of hydrogen bonding will be studied in future work using alternative methods, such as time-of-flight secondary ion mass spectroscopy, which can identify $\mathrm{AlOSi}^{+}$, suggesting covalent bonds over hydrogen bonding (Abel, Watts, \& Digby, 2004). Additionally, other methods, such as reflection absorption spectroscopy that are capable of increasing the absorbance intensity could be used to study the interfacial bonding between different functional groups and the aluminum oxide surface (Pluedemann, 1991; Van den Brand, Blajiev, Beentjes, Terryn, \& de Wit, 2004).

HAADF-STEM images confirmed the presence of a surface layer completely surrounding the aluminum particles. This can be seen in low-magnification images, such as Fig. 6(a), as a thin bright edge surrounding the particle. A brighter contrast in STEM images indicates a heavier mass for a uniform sample thickness. Higher magnification images (Fig. 6(b) and (c)) from representative regions around the edge of the particle clearly show this to be a bright layer approximately $10 \mathrm{~nm}$ thick. For comparison purposes, a conventional TEM image from the same region (Fig. 6(d)) shows the surface layer as dark, as would be expected for a region of higher mass. This layer is present over the entire surface of the particle. However, because the surface roughness of the particle is greater than the thickness of the layer, the overlapping contrast in the $2 \mathrm{D}$ projection at the particle edge makes it difficult to establish the uniformity of the layer. At even higher magnifications (Fig. 7(a)), it appears that there is actually another thin gray layer on top of the bright layer. EDS mapping at this magnification provided further insight into the manner in which the contrast of the two layers correlated with the elemental composition. A map of X-ray counts for just the silicon signal (Fig. 7(b)) in this region shows maximum silicon counts in the surface layers and the possible existence of a double silicon layer. By overlaying the HAADF image with the silicon map as well as the oxygen map (Fig. 7(c)), it is apparent that the bright layer correlates with the silicon signal and the outer gray layer correlates with the oxygen signal. An iron peak owing to the presence of this element as an impurity was also seen in the EDS spectrum, and the corresponding iron map also shows a correlation between the maximum iron X-ray counts and the bright layer.

Figs. $6 \& 7$

By quantifying the EDS spectrum at each point in the map, it is possible to extract a line profile of the atomic percent of each element across the surface layers. Fig. 8 plots the normalized atomic percentages of the 
five elements as functions of position at the location indicated in the corresponding HAADF image. There are two clear silicon peaks in the line profile. Moving from left to right, the first silicon peak is at the same position as the iron peak that corresponds to the bright layer in the image. After this peak, the oxygen atomic percent reaches a maximum and, as it tails off, the second silicon peak can be seen in the profile. This compositional profile explains the contrast of the bright layer, which is evidently due to the significantly heavier mass of the iron present in the layer.

Fig. 8

The extent of surface coverage has been demonstrated to have an effect on the flow, cohesion, and fluidization properties of surface-treated powders (Kim, Chen, \& Pearce, 2005; Zhou et al., 2011; Stank \& Steckel, 2013). In this work, the surface coverage by the PDMS was assessed qualitatively through imaging and found to be uniformly dispersed over the entire particle surface. As such, the flow and fluidization properties were enhanced, as will be discussed in the next section. Additional future studies will more precisely determine the extent of surface coverage through other characterization methods, including more thorough modeling using XPS, as previously demonstrated in the literature, and time-of-flight secondary ion mass spectroscopy as previously discussed with regard to the investigation of hydrogen bonding (Van den Brand et al., 2004; Kim et al., 2005; Zhou et al., 2011).

\subsection{Powder bulk properties}

Table 2 presents the classic density-based measurement values obtained for the raw and PDMS-treated aluminum powders. The raw powder had a tapped density of approximately $1.5 \mathrm{~g} / \mathrm{cm}^{3}$, which was increased by $14 \%$ with surface treatment to approximately $1.7 \mathrm{~g} / \mathrm{cm}^{3}$, indicating more efficient packing after surface treatment. Using analysis based on the Hausner ratio (Eq. (1)), the raw powder was classified as an "A-C" type powder, with an $H_{\mathrm{R}}$ of 1.38. The surface treatment reduced this value to 1.24, changing the Hausner group designation to "A" or aeratable, indicating that the adsorption of PDMS reduced the inter-particulate forces. The methyl groups on the PDMS backbone provide a hydrophobic coating that decreases void space and agglomeration owing to greater cohesiveness within the packed powder bed. The Carr index (Eq. (2)) of the powder was also decreased as a result of surface treatment, and the designation of this material was changed from a "very poor flowing" powder (30) to a "fair flowing" powder (19).

Table 2

The stability and variable flow rate tests probe the powder's robustness after multiple conditioning steps and record how the powder reacts to a variable tip speed measurement. These results are shown graphically in Fig. 9 and numerically in Table 2. This test also measures the BFE after each conditioning cycle, which is a 
baseline flow energy value for the work required to traverse the bed in a downward motion at a standard tip speed of $100 \mathrm{~mm} / \mathrm{s}$. Neither the untreated nor the treated powder exhibited any significant change in flow energy with additional conditioning cycles and thus both had stability indices of about unity. The higher initial BFE of the surface-treated powder was likely owing to the increased density of the material, which is consistent with the results obtained from the $H_{\mathrm{R}}$ measurements and additional findings that will be discussed later. The $F R I$ is a measure of how sensitive a powder is to varying flow environments and how it will behave under different offloading or processing conditions. Generally, more cohesive powders have a greater sensitivity to flow changes owing to increased entrained air and lower apparent density. When the FRI approaches unity, there is little to no change in the total flow energy at each speed, indicating the impact from variable tip speeds is inconsequential. The $F R I$ values for the raw and treated powders were found to be $1.74 \pm$ 0.01 and $1.67 \pm 0.04$, demonstrating a reduction in the sensitivity to flow rate.

Fig. 9

The specific energy (SE), or total energy measured during the upward traverse of the blade, is an indicator of how a powder will flow in an unconfined environment. Under these conditions, the effect of gravity is the largest consideration and thus the result is expressed in terms of mass to account for sample density differences. The effect gravity has on flow is also directly related to the inter-particulate cohesion; smaller particles tend to have inter-particulate forces that are greater than gravitational force, causing agglomeration and poor flow. As with the other flow measurements, the total energy tends to be higher with increased cohesive behavior. The raw powder had an $S E$ value of $3.8 \pm 0.1 \mathrm{~mJ} / \mathrm{g}$, whereas the PDMS-treated powder value was decreased to $3.1 \pm 0.1 \mathrm{~mJ} / \mathrm{g}$ (Table 2). The $S E$ was lowered with treatment, which is an additional result corroborating the observation of lower cohesion as a result of PDMS treatment.

The compressibility of a powder bed can indicate a powder's flowability and is the basic rationale for the CI. Although this is not a direct measurement of compressibility with varying normal stress, compressibility can be directly measured using the FT4. Compressibility curves for the raw and PDMS-treated powders are shown in Fig. 10 and confirm a lower compressibility following surface treatment (Table 2). The compressibility of the PDMS-treated powder at a consolidating pressure of $8 \mathrm{kPa}$ was lowered by approximately $32 \%$ compared with the raw state. This reduced sensitivity to compression indicates a reduction in void spaces owing to improved packing after surface treatment. These results agree with the calculated Carr index. A data set at varying normal stresses can be generated using this method and can be significantly more useful in process design and development.

Fig. 10 
Fig. 11 pictorially demonstrates the Mohr's circle analysis results and shear patterns observed at $6 \mathrm{kPa}$ for the raw and PDMS-treated powders, while Table 3 provides numerical values derived from this analysis. The UYS determines the amount of normal stress that will cause a plastic deformation of the powder bed, permitting a qualitative indication of surface particle interaction characteristics. The UYS $\left(\sigma_{1}\right)$ of the raw powder was $1.17 \mathrm{kPa}$, a value that was lowered by approximately $50 \%$ with surface treatment, to $0.52 \mathrm{kPa}$. This suggests a reduction in frictional forces because less shear stress is required to cause the particles to flow against one another. When there are strong cohesive forces, such as capillary bridging or hydrogen bonding, the bed can remain intact at higher consolidating pressures. In a flow application, this is a critical parameter because it will determine if the powder will flow freely through an orifice or if flow will be terminated owing to the bridging phenomenon (Freeman, 2007). From this analysis, an extrapolated cohesion value can be calculated at approximately zero applied normal stress by extending the yield loci regression to the $\mathrm{x}$-axis. The extrapolated cohesion value was decreased by $53 \%$ with surface treatment, while the $f f_{\mathrm{c}}$ at $6 \mathrm{kPa}$ was increased by $50 \%$.

Fig. 11

\subsection{Powder fluidization and permeability properties}

Aeration curves were generated by the calculating total energy values at increasing air velocities $(0.15-$ $0.6 \mathrm{~mm} / \mathrm{s}$ in $0.05-\mathrm{mm} / \mathrm{s}$ increments). As shown in Fig. 12, the aeration behavior of the raw powder was erratic. Visual observations indicated that rat-holing, spouting, and channeling behavior occurred with increasing air pressure. These phenomena likely formed pockets of entrained air within the powder bed, significantly changing the total energy values when these air pockets were released as the blade turned. The total energy value never dropped below $30 \mathrm{~mJ}$, suggesting that the bed was never completely fluidized. Portions of the powder bed were lifted at $>0.5 \mathrm{~mm} / \mathrm{s}$, and therefore meaningful measurements could not be collected beyond this point. The PDMS-treated powder exhibited less erratic aeration behavior; a sequential drop in total energy was observed at each $0.05-\mathrm{mm} / \mathrm{s}$ increment. The treated powder bed became uniformly fluidized at approximately $0.30 \mathrm{~mm} / \mathrm{s}$, at which point the total energy was less than $10 \mathrm{~mJ}$. The aeration ratio gives a qualitative indication of the powder's sensitivity to increasing air flow and its ability to become fluidized. As the aeration ratio approached unity, there was little to no sensitivity to the increasing air flow, which is typically the case for cohesive powders. As calculated using Eq. (4), the aeration ratio $(A R)$ increased to 4.8, an increase of about $63 \%$, indicating a free-flowing powder (Table 3). These data corroborate a decrease in inter-

particulate cohesion, as also demonstrated by the density and shear measurements, resulting from the hydrophobic character of the PDMS on the surfaces of the Al particles.

Fig. $12 \&$ Table 3 
The ability of air to flow through a powder bed depends on a number of factors. Here, the difference between the raw and treated powders results from changes in bulk density and cohesion, as the particle shape and distribution are nominally the same. As observed in the raw powder aeration tests, channeling and spouting behavior arose from large aggregates and agglomerates that prevented air from flowing freely past adjacent particles. The permeability of a powder is an important consideration for gas fluidization applications where consolidating loads could impact the powder's performance and the pressure required to produce a constant velocity could impart system constraints. The permeability test uses a constant air flow with varied consolidating pressures to measure the pressure drop through the powder bed.

Fig. 13 shows the permeability curves related to consolidating pressure for raw and PDMS-treated aluminum powders. The raw powder had a higher permeability (approximately 23\%) compared with the treated powder (Table 3), although the raw powder demonstrated greater sensitivity to the consolidating pressure, suggesting that the permeability was reduced with increases in the load. This is consistent with the higher compressibility of the raw powder, which would have had significant void space owing to channels and agglomerates. These features increased the air pressure needed to maintain a constant flow velocity throughout the powder bed. The treated powder, however, showed lower permeability, which is counter-intuitive in conjunction with a reduction in cohesion. This result can likely be attributed to the increased density of the raw powder, resulting from more effective packing, as can be seen from Table 2.

Fig. 13

\section{Conclusions}

The specific goal of the surface treatment methodology discussed herein was to reduce the cohesiveness and improve the flowability of aluminum powder using the gas phase deposition of an alkoxysilane analog. The following conclusions were drawn from the results:

1. This study has shown that PDMS can be deposited on metallic aluminum particles using a fluidized bed reactor. The retention of PDMS was verified using XPS and DRIFTS spectroscopy. Each technique showed spectral features indicating that the Si-O-Si backbone was maintained and not disrupted through heating or gas phase delivery.

2. As a consequence of conclusion 1, PDMS surface treatment increased the bulk density of the aluminum powder. Classical methods for characterizing powder flowability based on density differences categorized the PDMS-treated powder as aeratable by the Hausner ratio, which was not the case before surface treatment. The Carr index classified the treated powder as having fair flow properties, whereas the raw powder was categorized as very poorly flowing. 
3. Conclusion 2 was a result of the reduction of inter-particulate cohesion, which was demonstrated through various dynamic powder testing methods using the FT4 powder rheometer. This was confirmed through lower compressibility, the reduction of cohesion in Mohr circle analysis, and improved fluidization behavior after surface treatment.

\section{Acknowledgments}

This work was supported by the Office of Naval Research under Grant No. N00014-14-1-0692. The authors are grateful to Mrs. Maria Medeiros for securing funding this effort, Shawn Ward for his assistance with fabrication of the fluidized bed reactor, and Josh Maier, who prepared the FIB samples. All opinions, findings, conclusions, and recommendations expressed in this paper are those of the authors and do not necessarily reflect the views of the Office of Naval Research.

\section{References}

Abel, M. L., Watts, J. F., \& Digby, R. P. (2004). The influence of process parameters on the interfacial chemistry of gamma-GPS on aluminum: A review. The Journal of Adhesion, 80(4), 291-312.

Al-Abadleh, H. A., \& Grassian, V. H. (2003). FT-IR study of water adsorption on aluminum oxide surfaces. Langmuir, 19, 341-347.

Bishay, I. K., Abd-El-Messieh, S. L., \& Mansour, S. H. (2011). Electrical, mechanical, and thermal properties of polyvinyl chloride composites filled with aluminum powder. Materials \& Design, 32, 62-68.

Brochier Salon, M.C., \& Belgacem, M.N. (2010). Competition between hydrolysis and condensation reactions of trialkoxysilanes, as a function of the amount of water and the nature of the organic group. Colloids and Surfaces A, 366, 147-154.

Carr, R.L. (1965). Evaluating flow properties of solids. Chemical Engineering, 72, 163-168.

Darcy, H. (1856). Les fontaines publiques de la ville de Dijon. Paris: Dalmont.

Diggle, E. J. W., \& Ashok, K. (1976). Oxides and oxide-films. New York: Marcel Dekker Inc.

Dobias, B., Qiu, X., \& von Rybinski, W. (Eds.). (1999). Solid-liquid dispersions. Boca Raton: CRC Press.

Freeman, R. (2007). Measuring the flow properties of consolidated, conditioned, and aerated powders - A comparative study using a powder rheometer and a rotational shear cell. Powder Technology, 174, 25-33. 
Freeman, T. C., Freeman, R. E., \& Armstrong, B. (2011). The characterization of powder and bulk material A multivariate approach using dynamic, shear, and bulk property measurements. Bulk Solids India, (April $\left.6^{\text {th }}-8^{\text {th }}, 2011\right)$.

Hausner, H.H. (1967). Friction conditions in a mass of metal powder. International Journal of Powder Metallurgy, 3, 7-13.

Hunter, M. S., \& Fowle, P. (1956). Natural and thermally formed oxide films on aluminum. Journal of the Electrochemical Society, 482-485.

Karlsson, P., Palmqvist, A. E., \& Holmberg, K. (2006). Surface modification for aluminum pigment inhibition. Advances in Colloids and Interfaces, 128, 121-134.

Kim, E. H. J., Chen, X. D., \& Pearce, D. (2005). Effect of surface composition on the flowability of industrial spray-dried dairy powders. Colloids and Surfaces B: Biointerfaces, 46, 182-187.

Kim, Y. H., Jeong, M. G., Seo, H. O., Park, S. Y., Jeong, I. B., \& Kim, K. D., et al. (2012). Preparation of ultrathin polydimethylsiloxane-coating on $\mathrm{Cu}$ as oxidation-protection layer. Applied Surface Science, 258(19), 7562-7566.

Kuchibhatla, S. V., Karakoti, A. S., \& Seal, S. (2005). Colloidal stability by surface modification. Journal of Materials, 12, 52-56.

Kurth, D. G., \& Bein, T. (1992). Monomolecular layers and thin films of silane coupling agents by vaporphase adsorption on oxidized aluminum. The Journal of Physical Chemistry, 96(16), 6707-6712.

Lawley, A. (1992). Atomization: The production of metal powders. Metal Powder Industries Federation, USA.

Ludwig, B., \& Miller, T. F. (2015). Rheological and surface chemical characterization of alkoxysilane treated, fine aluminum powders showing enhanced flowability and fluidization behavior for delivery applications. Powder Technology, 283, 380-388.

Mamunya, Y. P., Davydenko, V. V., Pissis, P., \& Lebedev, E. V. (2002). Electrical and thermal conductivity of polymers filled with metal powders. European Polymer Journal, 38, 1887-1897.

Masuda, H., Higashitani, K., \&Yoshida, H. (Eds.) (2006). Powder technology handbook (3 ${ }^{\text {rd }}$ Ed.). Boca Raton: CRC Press 
Montemor, M.F. (2014). Functional and smart coatings for corrosion protection: A review of recent advances. Surface and Coatings Technology, 258, 17-37.

Morterra, C., \& Magnacca, G. (1996). A case study: Surface chemistry and surface structure of catalytic alumina as studied by vibrational spectroscopy of adsorbed species. Catalysis Today, 27, 497-532.

Moulder, J. F., Stickle, W. F., Sobol, P. E., \& Bomben, K. D. (1993). Handbook of X-ray photoelectron spectroscopy. Perkin-Elmer Corporation, Physical Electronics Division: Eden Prairie, Minnesota 40-41, $56-57$.

Park, E. J., Sim, J. K., Jeong, M. G., Seo, H. O., \& Kim, Y. D. (2012). Transparent and superhydrophobic films prepared with polydimethylsiloxane-coated silica nanoparticles. RSC Advances, 3(31), 1257112576.

Pluedemann, E.P. (1991). Silane coupling agents. New York: Plenum Press.

Romanenko, E. A., \& Tkachuk, B. V. (1973). Infrared spectra and structure of thin polydimethylsiloxane films. Journal of Applied Spectroscopy, 18(2), 188-192.

Schulze, D. (2008). Powders and bulk solids: Behaviour, characterization, storage and flow. Berlin: Springer.

Smith, A.L. (1960). Infrared spectra-structure correlations for organosilicon compounds. Spectrochimica Acta, 16(1-2), 87-105.

Stank, K., \& Steckel, H. (2013). Physico-chemical characterisation of surface modified particles for inhalation. International Journal of Pharmaceutics, 448(1), 9-18.

Stratmann, M., Feser, R., \& Leng, A. (1994). Corrosion protection by organic films. Electrochimica Acta, 39(8-9), 1207-1214.

Van den Brand, J., Blajiev, O., Beentjes, P. C. J., Terryn, H., \& de Wit, J. H. W. (2004). Interaction of ester functional groups with aluminum oxide surfaces using infrared reflection absorption spectroscopy. Langmuir, 20, 6318-6326.

Yuan, J., Liu, X., Akbulut, O., Hu, J., Suib, S. L., \& Kong, J., et al. (2008). Superwetting nanowire membranes for selective absorption. Nature Nanotechnology, 3(6), 332-336. 
Zhou, Q. T., Qu, L., Gengenbach, T., Denman, J. A., Larson, I., \& Stewart, P. J., et al. (2011). Investigation of the extent of surface coating via mechanofusion with varying additive levels and the influences on bulk powder flow properties. International Journal of Pharmaceutics, 413(1), 36-43. 


\title{
The effect of gas phase polydimethylsiloxane surface treatment of metallic aluminum particles: Surface characterization and flow behavior
}

\author{
Bellamarie Ludwig ${ }^{\mathrm{a}, *}$, Jennifer L. Gray ${ }^{\mathrm{b}}$
}

\section{Tables:}

Table 1. XPS surface atomic percentage compositions for raw and PDMS-treated powders

\begin{tabular}{ccccccccc}
\hline \multirow{2}{*}{ type } & \multicolumn{3}{c}{$\mathrm{C}$} & \multicolumn{3}{c}{$\mathrm{O}$} & \multicolumn{3}{c}{$\mathrm{Si}$} \\
\cline { 2 - 8 } & $\mathrm{C}=\mathrm{O}$ & $\mathrm{C}-\mathrm{O}$ & $\mathrm{CH}$ & $\mathrm{O}-\mathrm{Al} / \mathrm{Si}$ & $\mathrm{O}-\mathrm{C}$ & $\mathrm{Si}-\mathrm{O}$ & $\mathrm{Al}-\mathrm{O}$ & $\mathrm{Al}$ \\
\hline Raw & 2.3 & 5.3 & 13.1 & 38.1 & 10.5 & - & 24.6 & 6.0 \\
PDMS-treated & 1.3 & 1.8 & 11.8 & 50.8 & - & 2.6 & 25.4 & 6.3 \\
\hline
\end{tabular}

Table 2. Bulk properties of raw and PDMS-treated aluminum powder (standard deviations in parentheses where $n \geq 3$ and where appropriate)

\begin{tabular}{cccccccc}
\hline State & $\begin{array}{c}\rho_{\mathrm{T}} \\
\left(\mathrm{g} / \mathrm{cm}^{3}\right)\end{array}$ & $H_{\mathrm{R}}$ & $C I$ & $S I$ & $F R I$ & $\begin{array}{c}S E \\
(\mathrm{~mJ} / \mathrm{g})\end{array}$ & $\begin{array}{c}\text { Compressibility } \\
\text { at } 8 \mathrm{kPa}(\%)\end{array}$ \\
\hline Raw & $1.5(0.1)$ & 1.36 & 30 & 0.95 & $1.74(0.01)$ & $3.76(0.04)$ & $8.0(0.5)$ \\
PDMS-treated & $1.7(0.1)$ & 1.24 & 18 & 0.98 & $1.67(0.04)$ & $3.13(0.12)$ & $5.5(0.3)$ \\
\hline
\end{tabular}

Table 3. Flow and aeration properties of raw and PDMS-treated aluminum powder (standard deviations in parentheses where $n \geq 3$ and where appropriate)

\begin{tabular}{cccccccc}
\hline & $c$ & & $A E$ & & $k$ & \\
State & $(\mathrm{kPa})$ & $(\mathrm{kPa})$ & $f f_{\mathrm{c}}$ & $\begin{array}{c}\text { at } 0.5 \mathrm{~mm} / \mathrm{s} \\
(\mathrm{mJ})\end{array}$ & $A R$ & $\begin{array}{c}\text { at } 0.2 \mathrm{~mm} / \mathrm{s} \\
\left(\mathrm{cm}^{2}\right)\end{array}$ & $\begin{array}{c}\text { Category } \\
\end{array}$ \\
& $0.38(0.03)$ & $1.17(0.03)$ & 8 & 6.18 & 1.8 & $3.91(0.09)$ & Easy flowing \\
\hline Raw & $0.18(0.05)$ & $0.52(0.03)$ & 16 & 20.2 & 4.8 & $3.01(0.08)$ & Free flowing \\
\hline
\end{tabular}




\title{
The effect of gas phase polydimethylsiloxane surface treatment of metallic aluminum particles: Surface characterization and flow behavior
}

\author{
Bellamarie Ludwig ${ }^{\mathrm{a} *}$, Jennifer L. Gray ${ }^{\mathrm{b}}$
}

\section{Figure captions:}

Fig. 1. Schematic of the polydimethylsiloxane (PDMS) gas deposition apparatus.

Fig. 2. Particle size distributions by volume percent of the raw (dashed) and PDMS-treated (solid) aluminum particles, showing no changes within experimental error after surface treatment (averages of three measurements are shown).

Fig. 3. Scanning electron micrograph of the spherical gas-atomized aluminum powder.

Fig. 4. (a) X-ray photoelectron spectroscopy (XPS) survey showing raw (dashed) and PDMS treated (solid) aluminum powder with silicon 1s and $2 \mathrm{p}$ peaks indicated; (b) high-resolution plot of the silicon $2 \mathrm{p}$ peak of the treated aluminum, demonstrating the retention of PDMS; and (c) high-resolution plot of the carbon 1s peak of the aluminum powder, showing various types of carbon surface content.

Fig. 5. Diffuse reflectance Fourier transform infrared spectroscopy (DRIFTS) spectra of raw (dashed) and PDMS-treated (solid) aluminum powder. The treated powder exhibits peaks attributed to $\mathrm{Al}-\mathrm{O}, \mathrm{Si}-\mathrm{O}-\mathrm{Si}$, and $-\mathrm{CH}_{3}$ moieties present on the surface, all characteristic of PDMS.

Fig. 6. (a) Scanning transmission electron microscopy (STEM) top-view image of a particle cross-section showing approximately one fourth of the aluminum particle; (b) higher magnification image of the surface layer; (c) higher magnification image of the lower region of the particle; and (d) corresponding TEM image for the same location as shown in (c).

Fig. 7. (a) STEM high-angle annular dark field (HAADF) image of the region over which energy dispersive spectroscopy (EDS) mapping was performed; (b) silicon EDS map; (c) HAADF image overlayed with silicon and oxygen maps; and (d) HAADF image overlayed with iron and oxygen maps.

Fig. 8. Quantified EDS profile of atomic percent across the surface of the particle at position shown in STEM HAADF image to right. 
Fig. 9. Stability and variable flow rate assessment of raw (solid) and PDMS-treated (dashed) powder velocity values (error bars represent standard deviations where $n \geq 3$ ).

Fig. 10. Compressibility measurements from 1 to $8 \mathrm{kPa}$ for raw (dashed) and PDMS-treated (solid) powders. PDMS treatment lowered the overall compressibility of the powder, indicating reduction of inter-particulate forces (error bars represent standard deviations where $n \geq 3$ ).

Fig. 11. Yield loci produced at increasing applied normal stress (2-4 kPa) for raw (dashed) and PDMS-treated (solid) aluminum powders. Mohr's circle analysis indicated lower cohesion and unconfined yield strength (UYS) with surface treatment.

Fig. 12. Flow energy curves of raw (dashed) and PDMS-treated (solid) powders from 0 to $0.65 \mathrm{~mm} / \mathrm{s}$ air velocity. Erratic flow behavior was observed for the raw powder whereas the treated powder became uniformly fluidized at less than $0.35 \mathrm{~mm} / \mathrm{s}$ air velocity (error bars represent standard deviations where $n \geq 3$ ).

Fig. 13. Permeability measurements from 1 to $8 \mathrm{kPa}$ at $6.0 \mathrm{~mL} / \mathrm{min}$ air flow rate for raw (dashed) and PDMStreated (solid) powders. The higher pressure drop for the treated sample is owed to the increased density with surface treatment (error bars represent standard deviations where $n \geq 3$ ). 
<smiles>[R][R]O[Si](C)(C)O[R][R]</smiles>

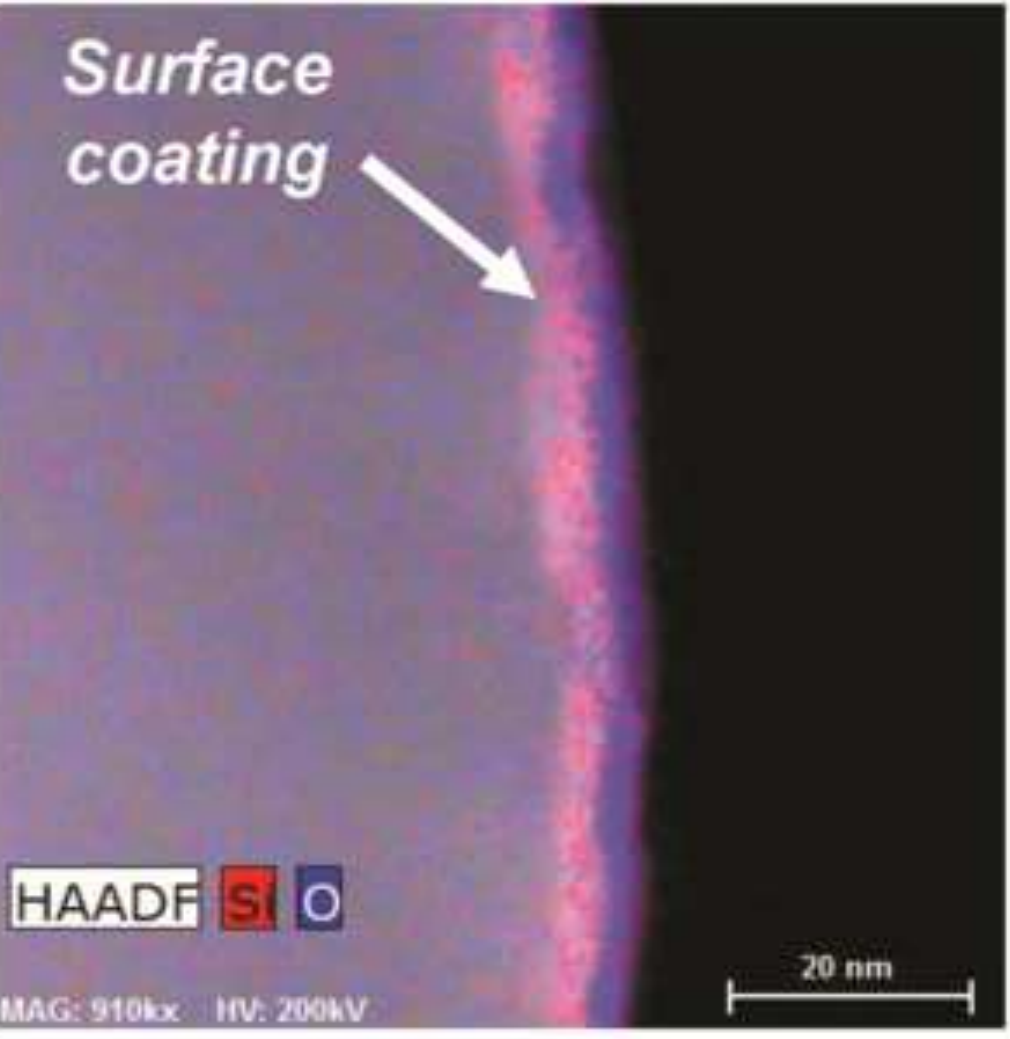

Metallic Al

Particles
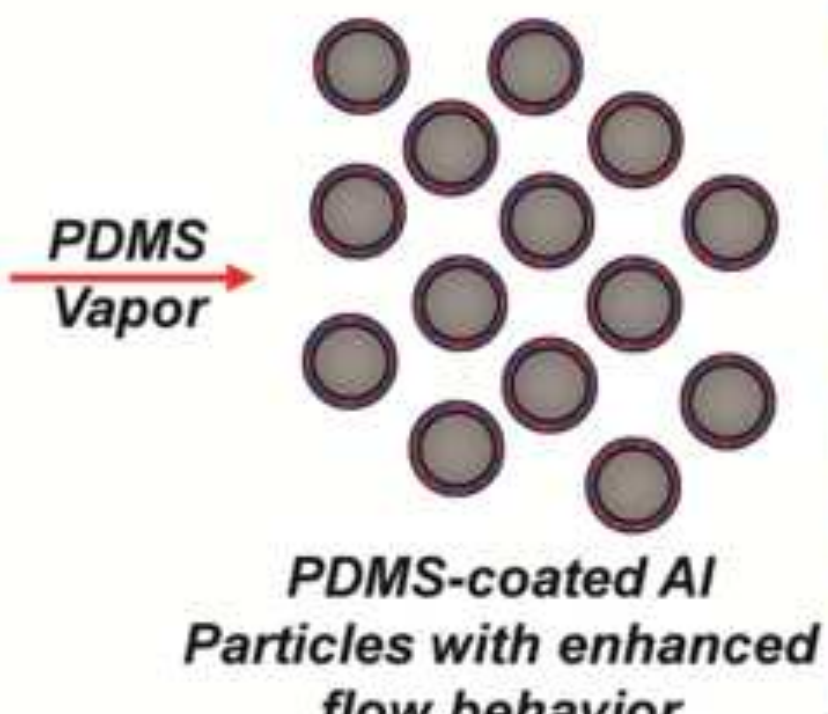

flow behavior 


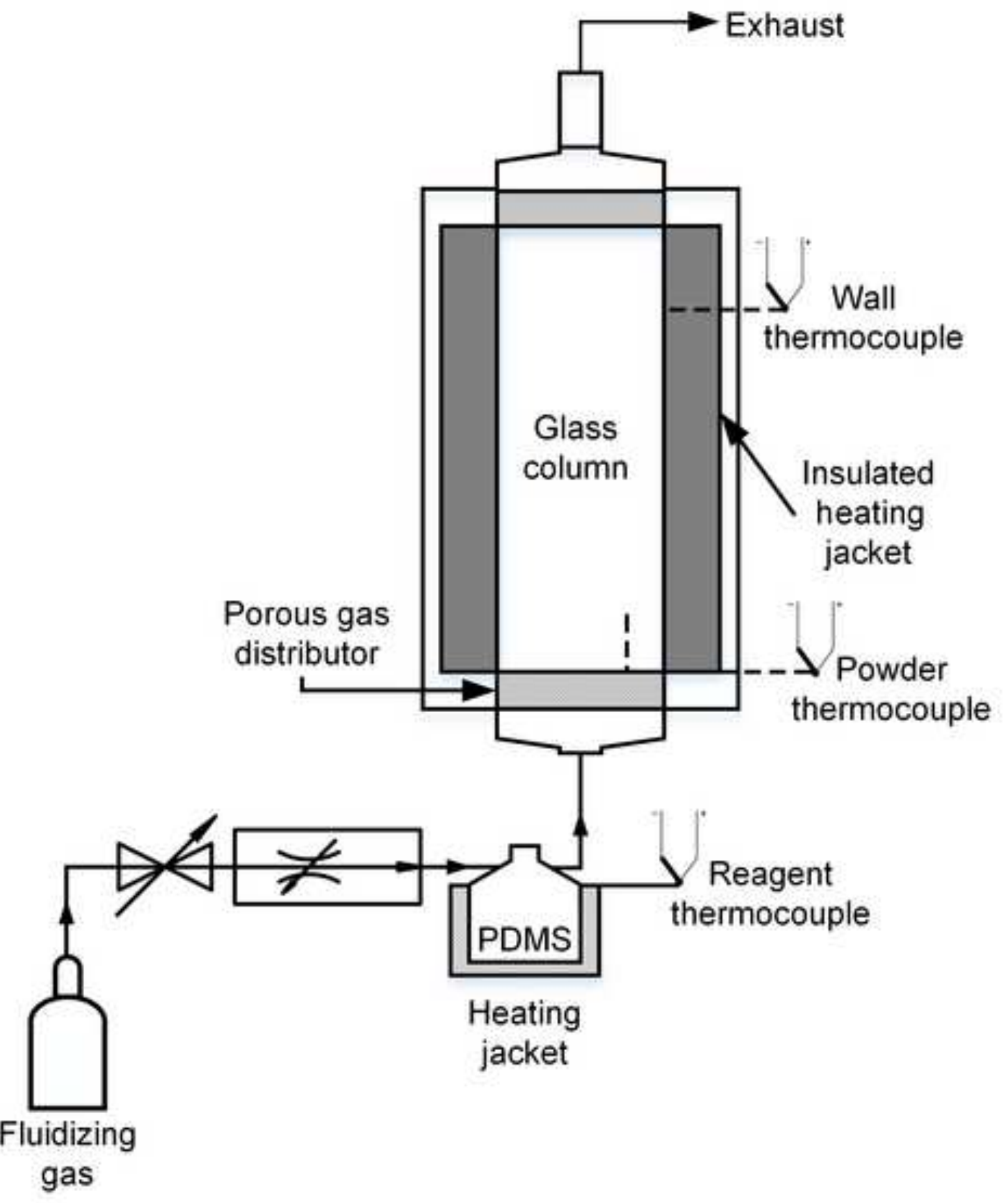




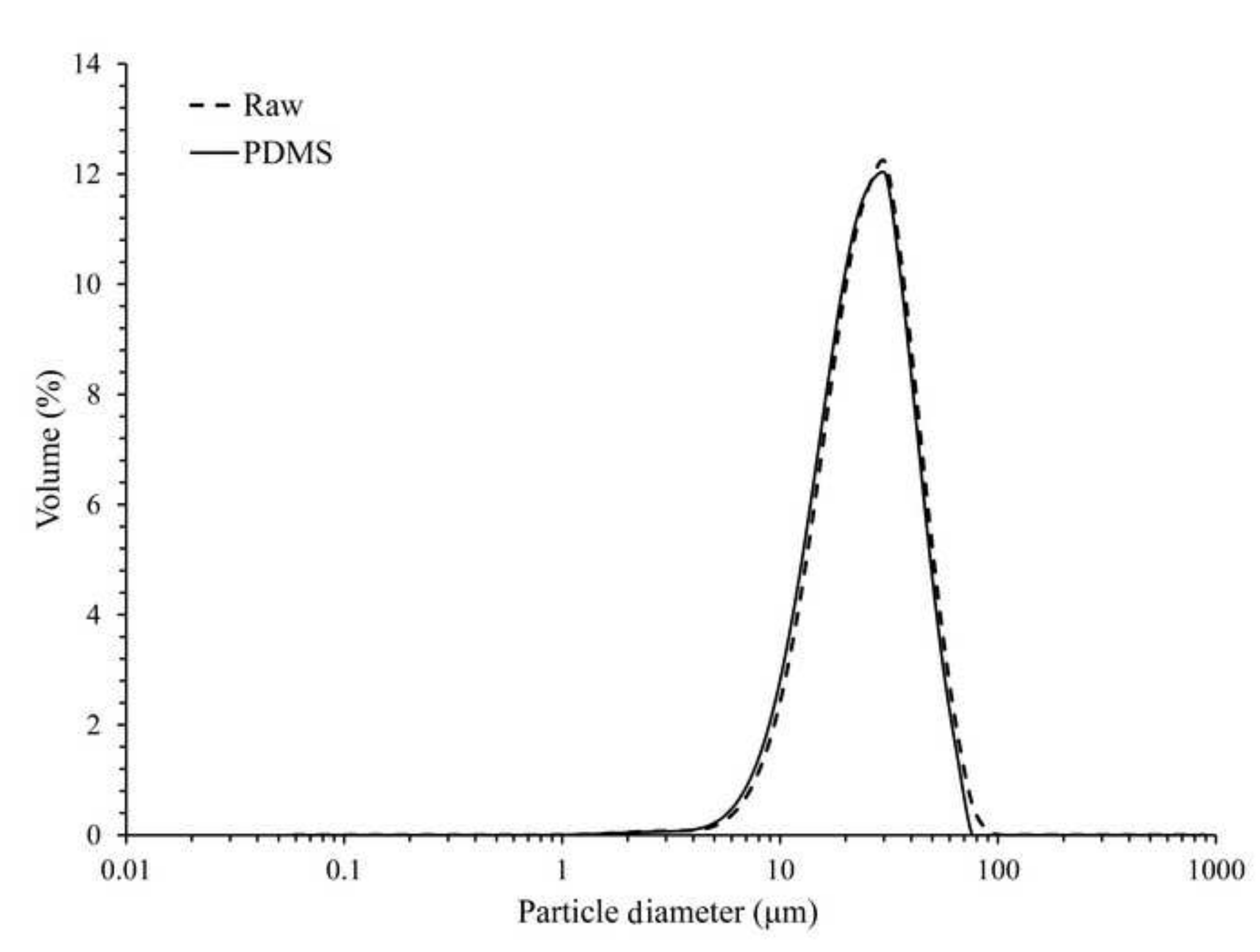




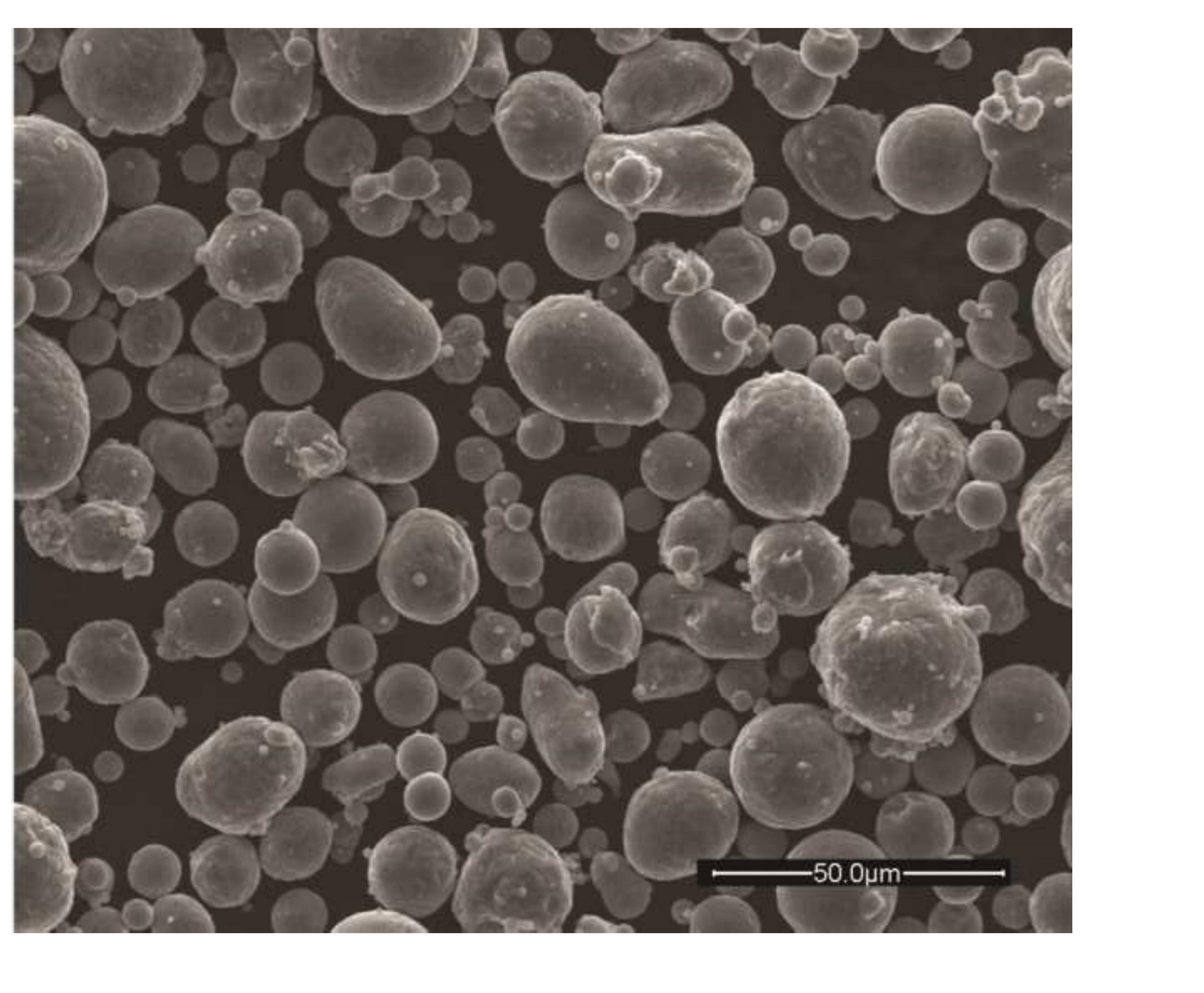

.

.
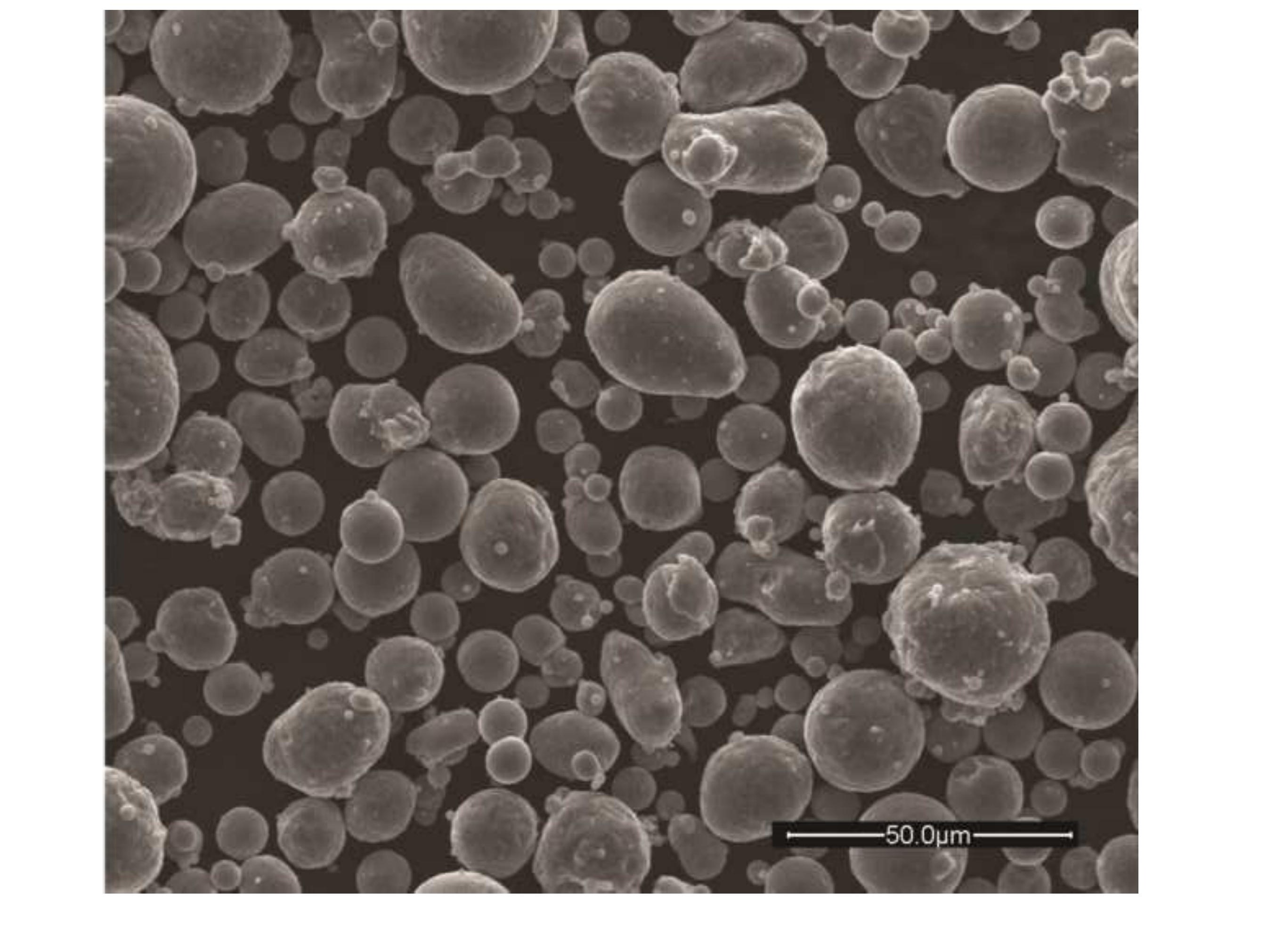


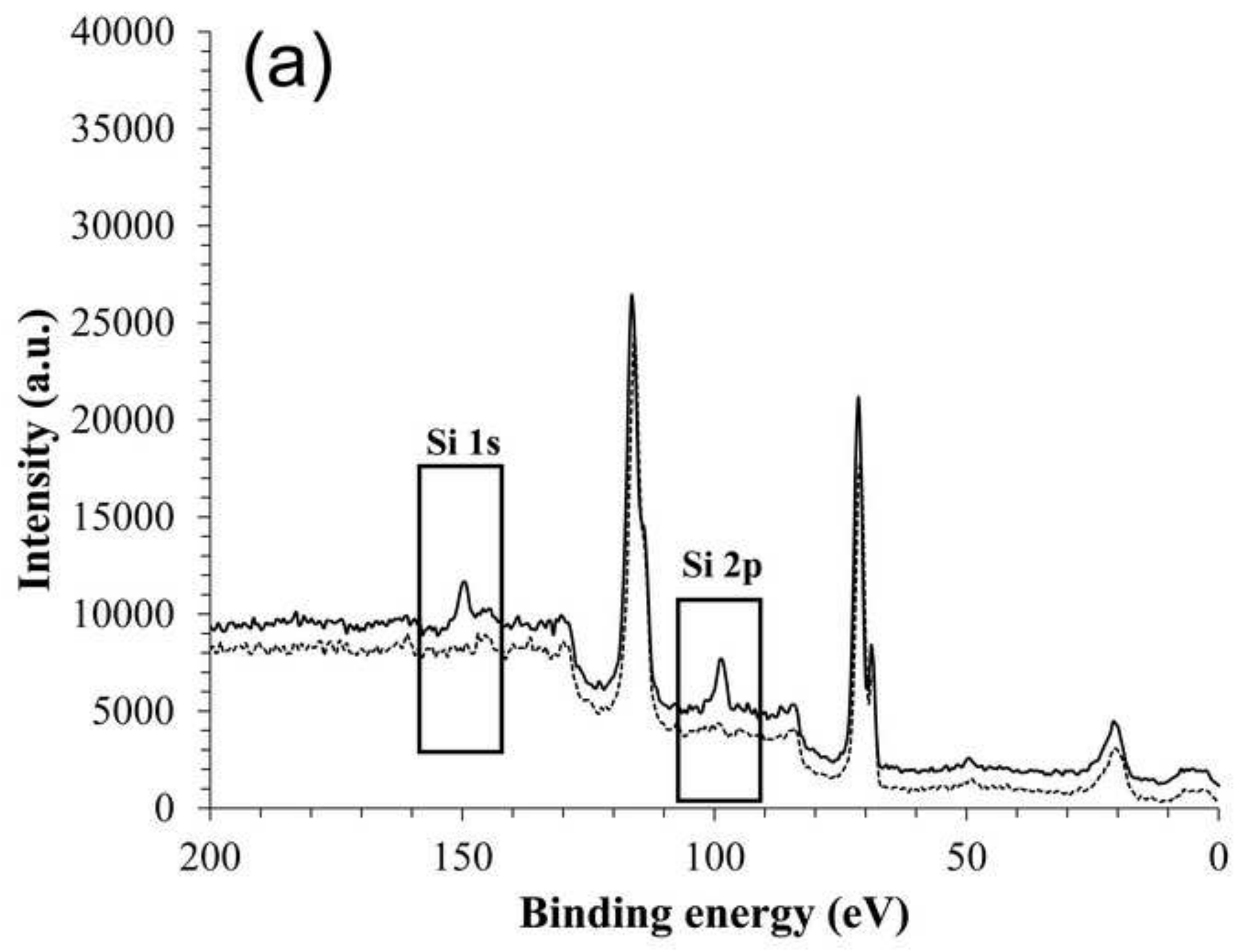




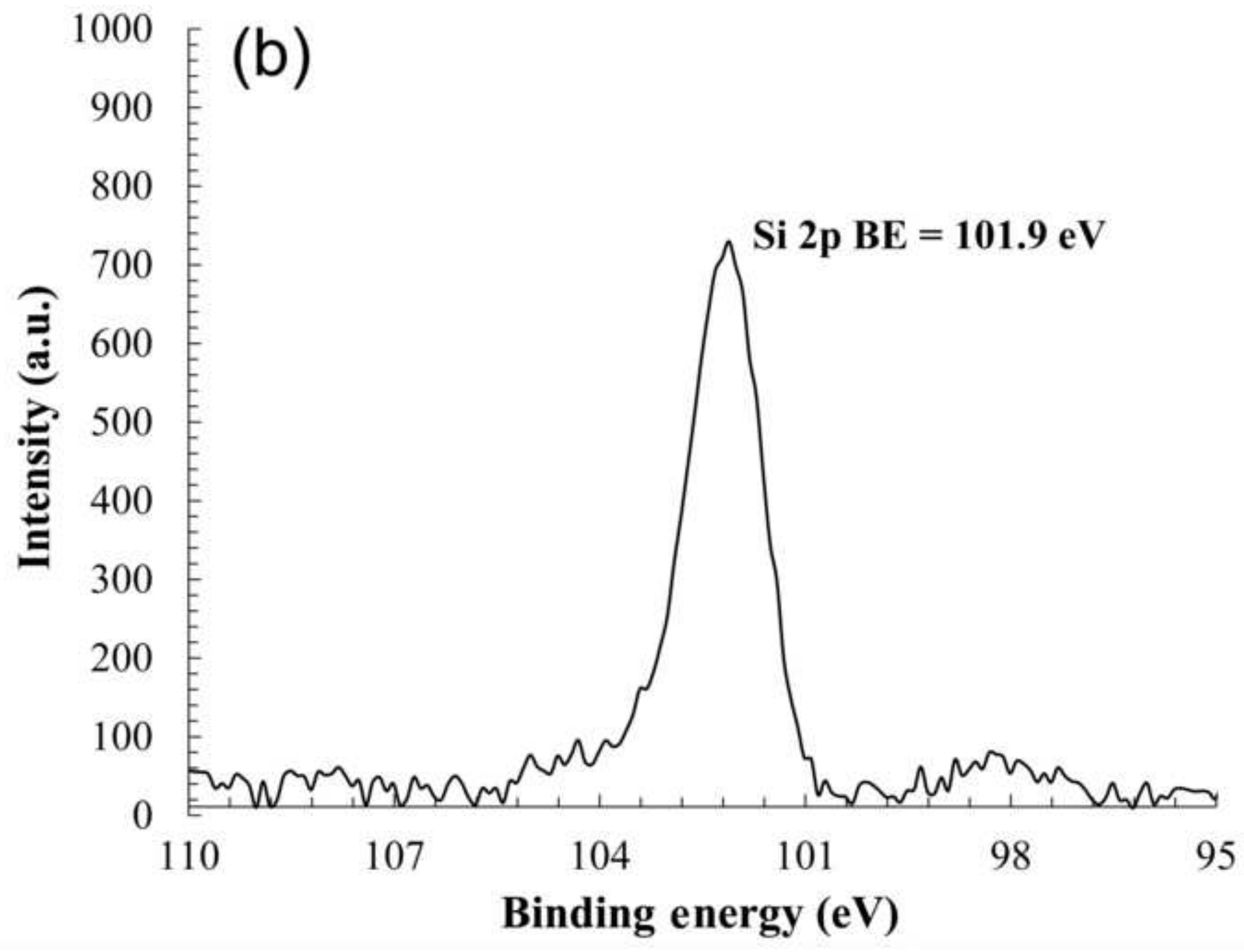




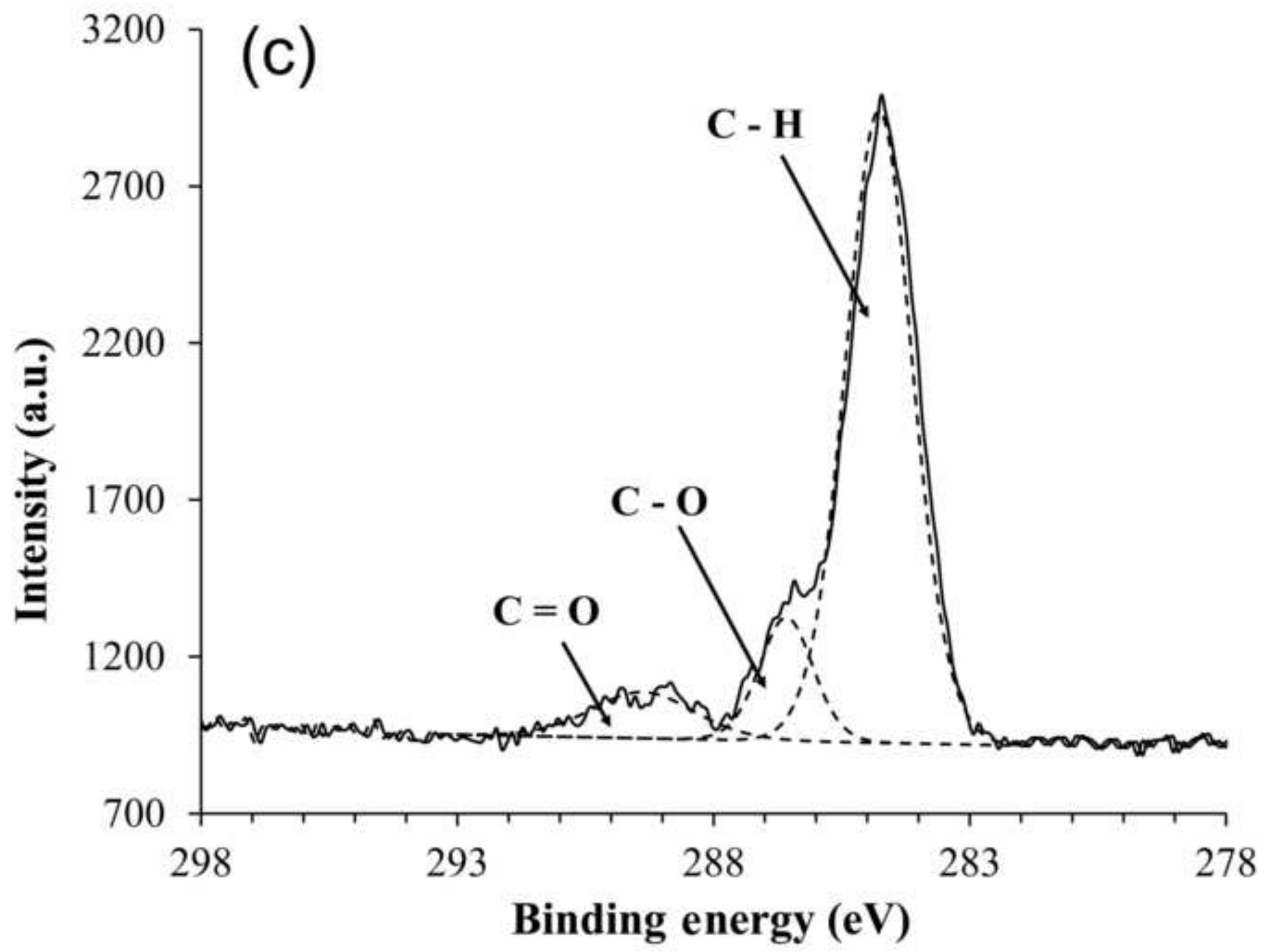




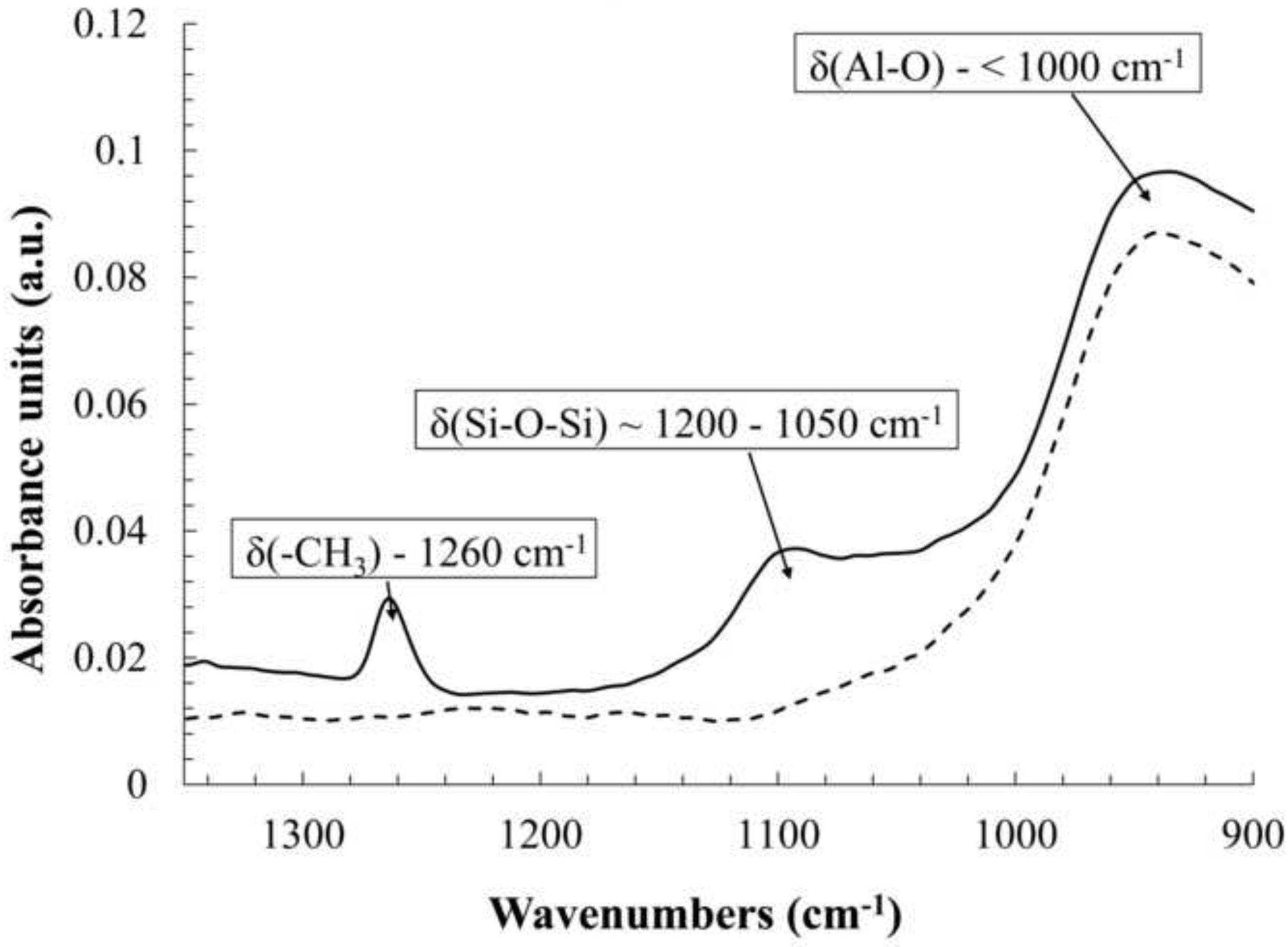




\section{Carbon}

\section{Aluminum}

\section{particle}

\section{Surface}

layer

\section{coating}
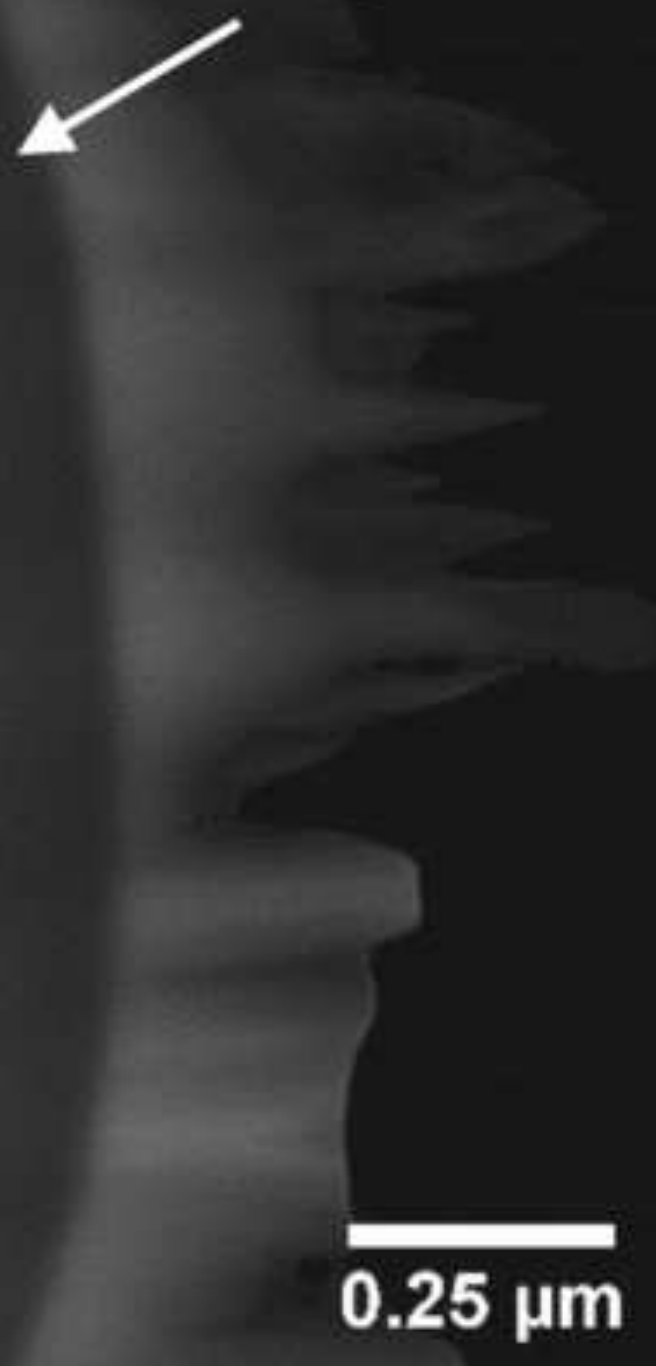


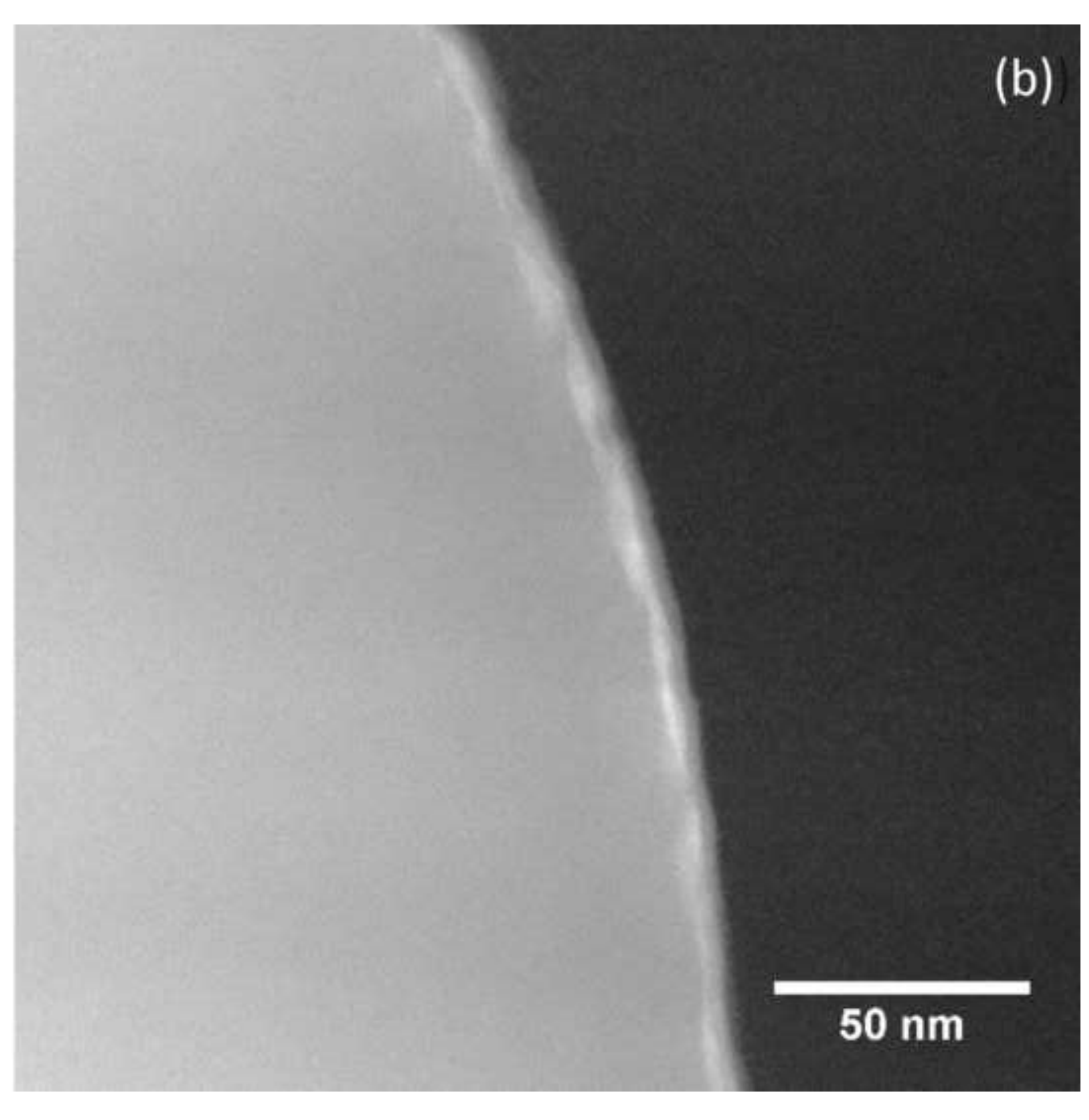

.

(1)

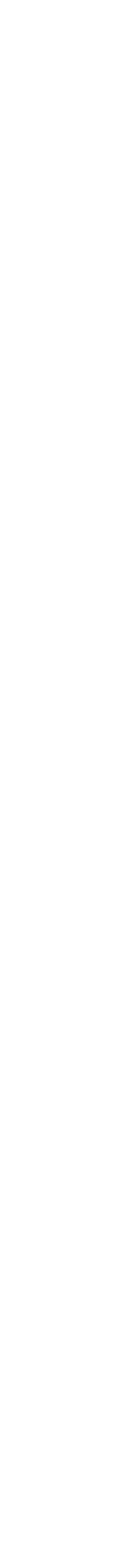 \\ $50 \mathrm{~nm}$}

.
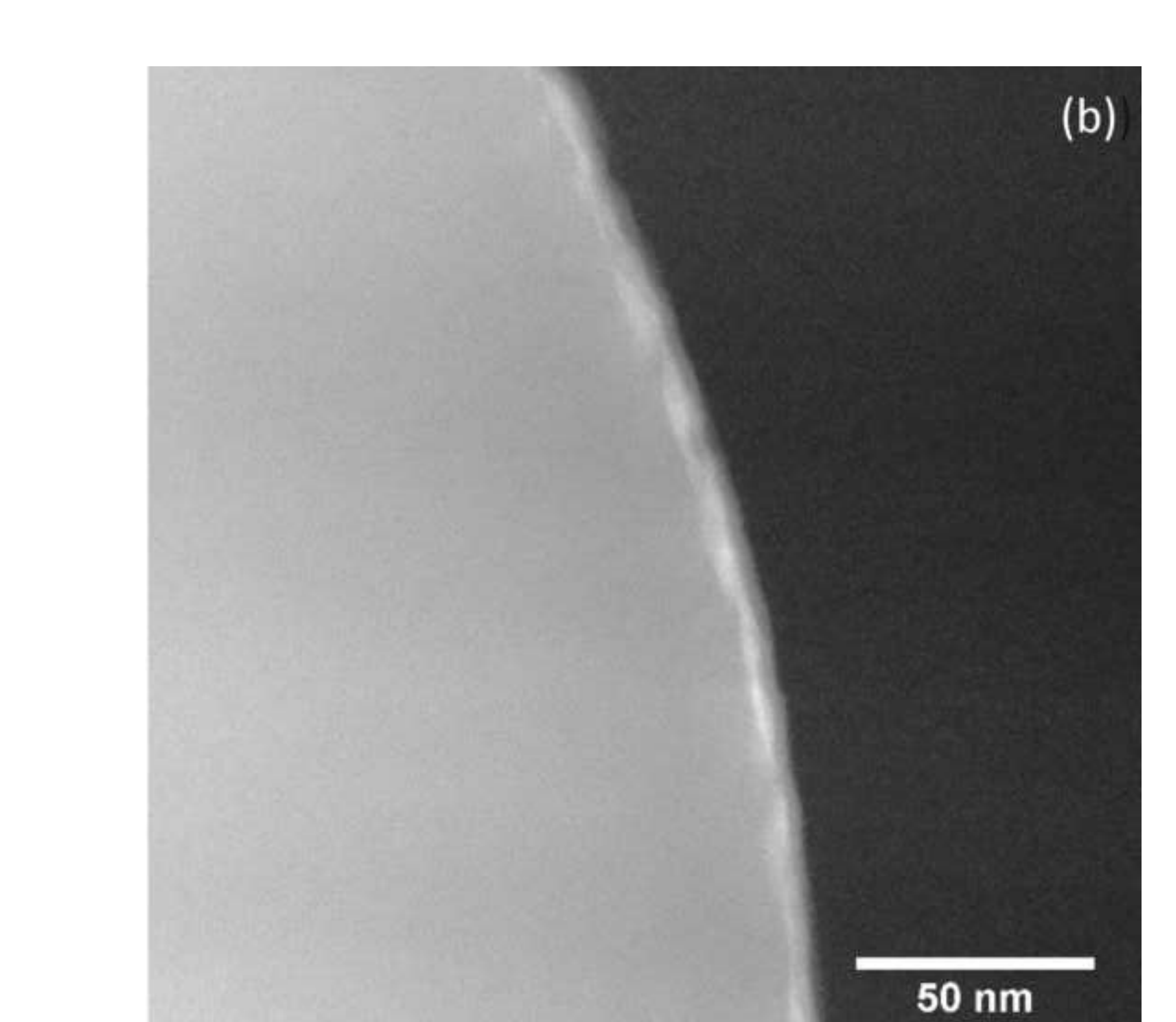

.
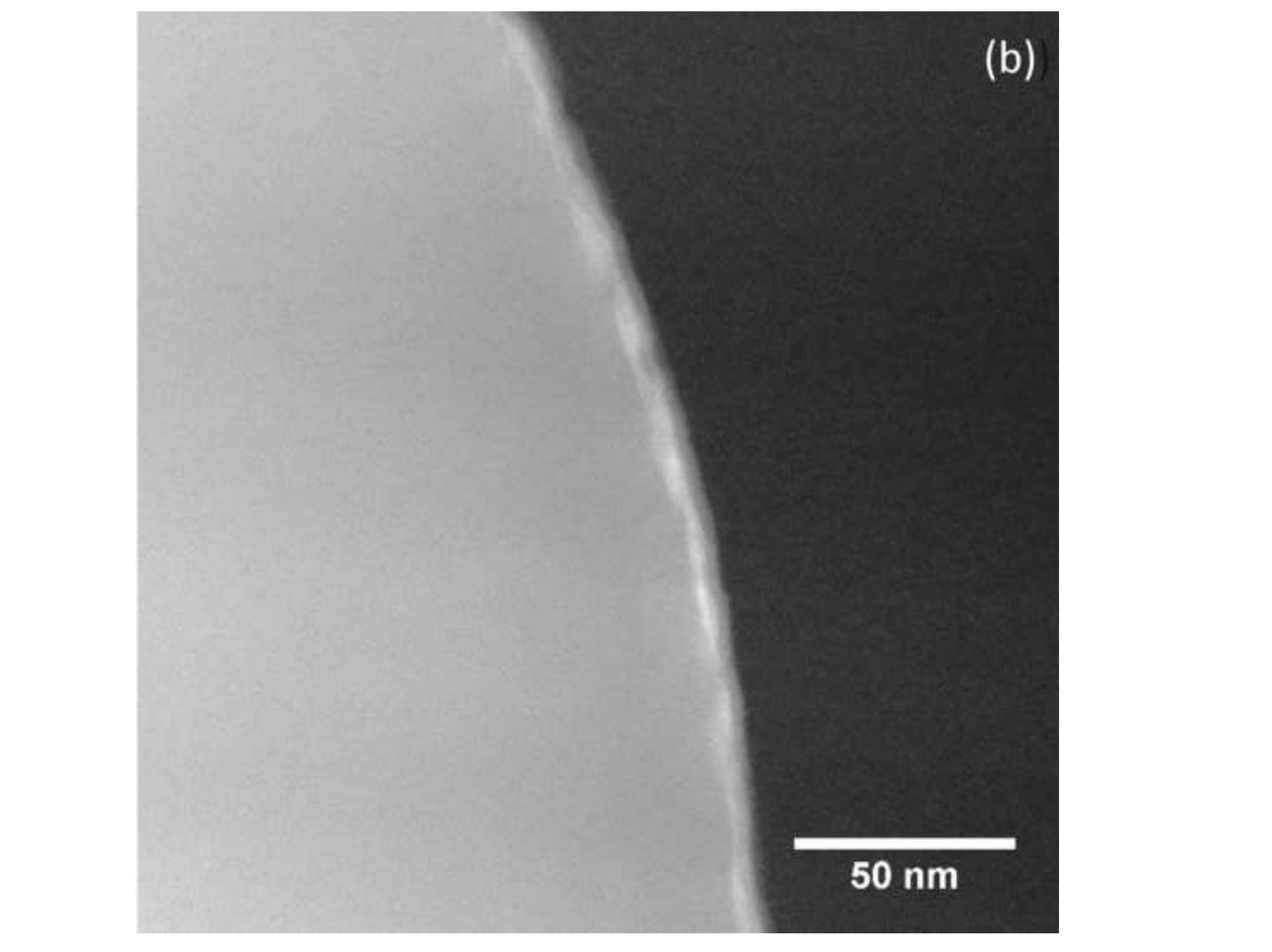

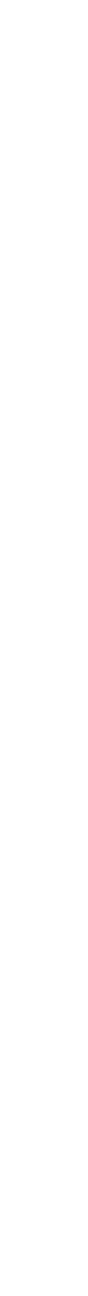


fig 6c.tif

(c)

\section{$50 \mathrm{~nm}$}




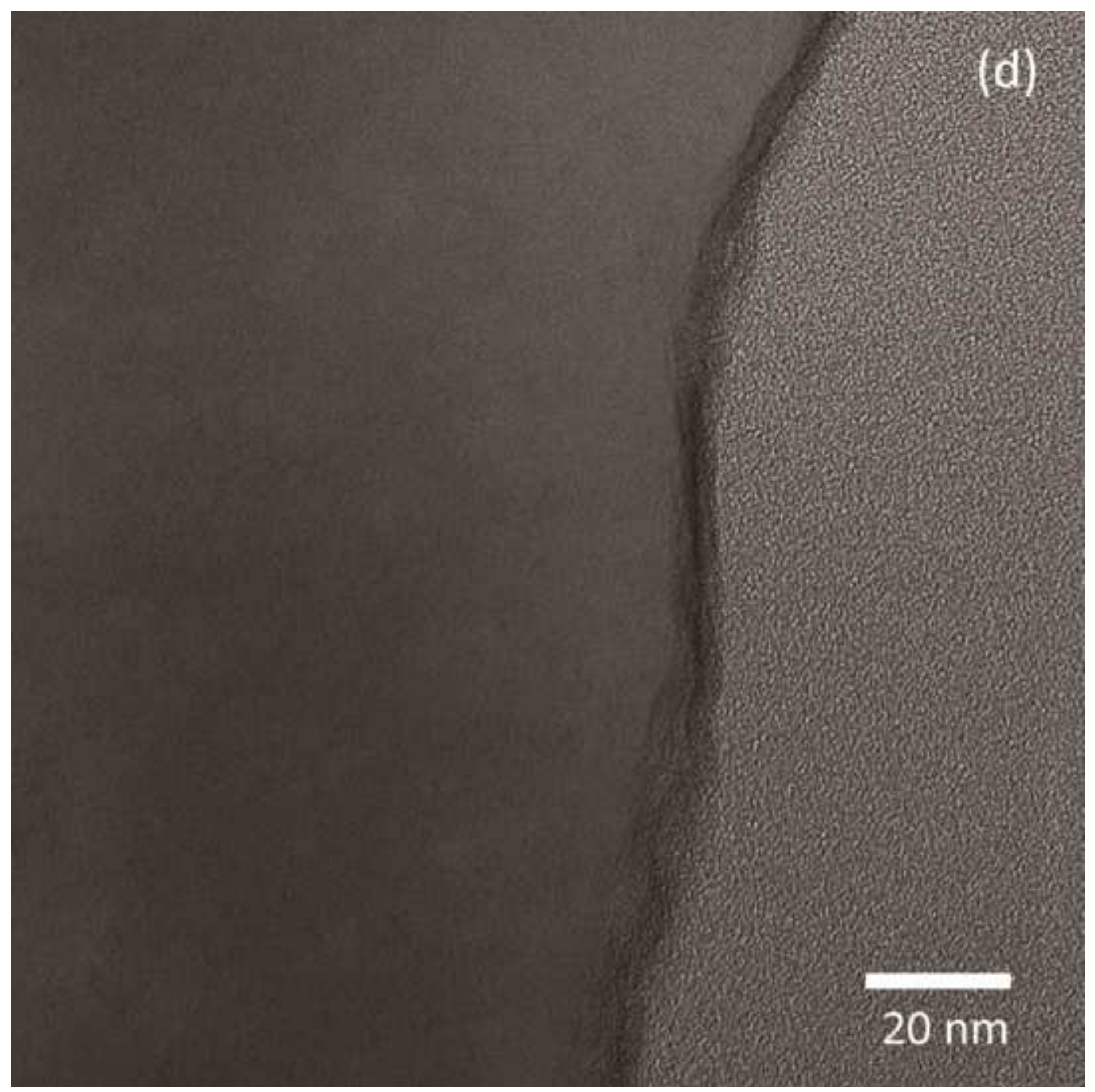
. 


\section{HAADF

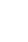

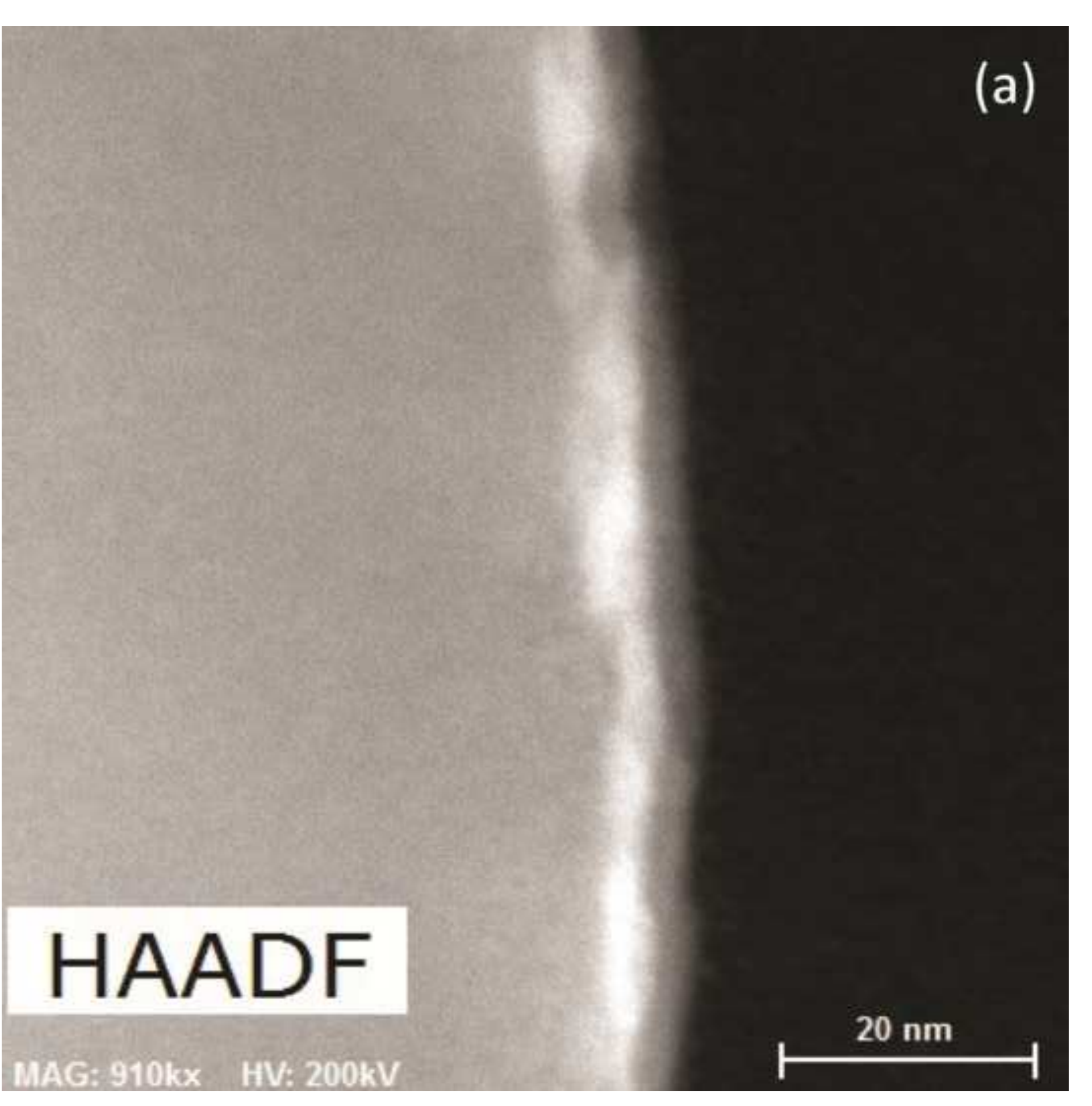




\section{fig 7b.tif

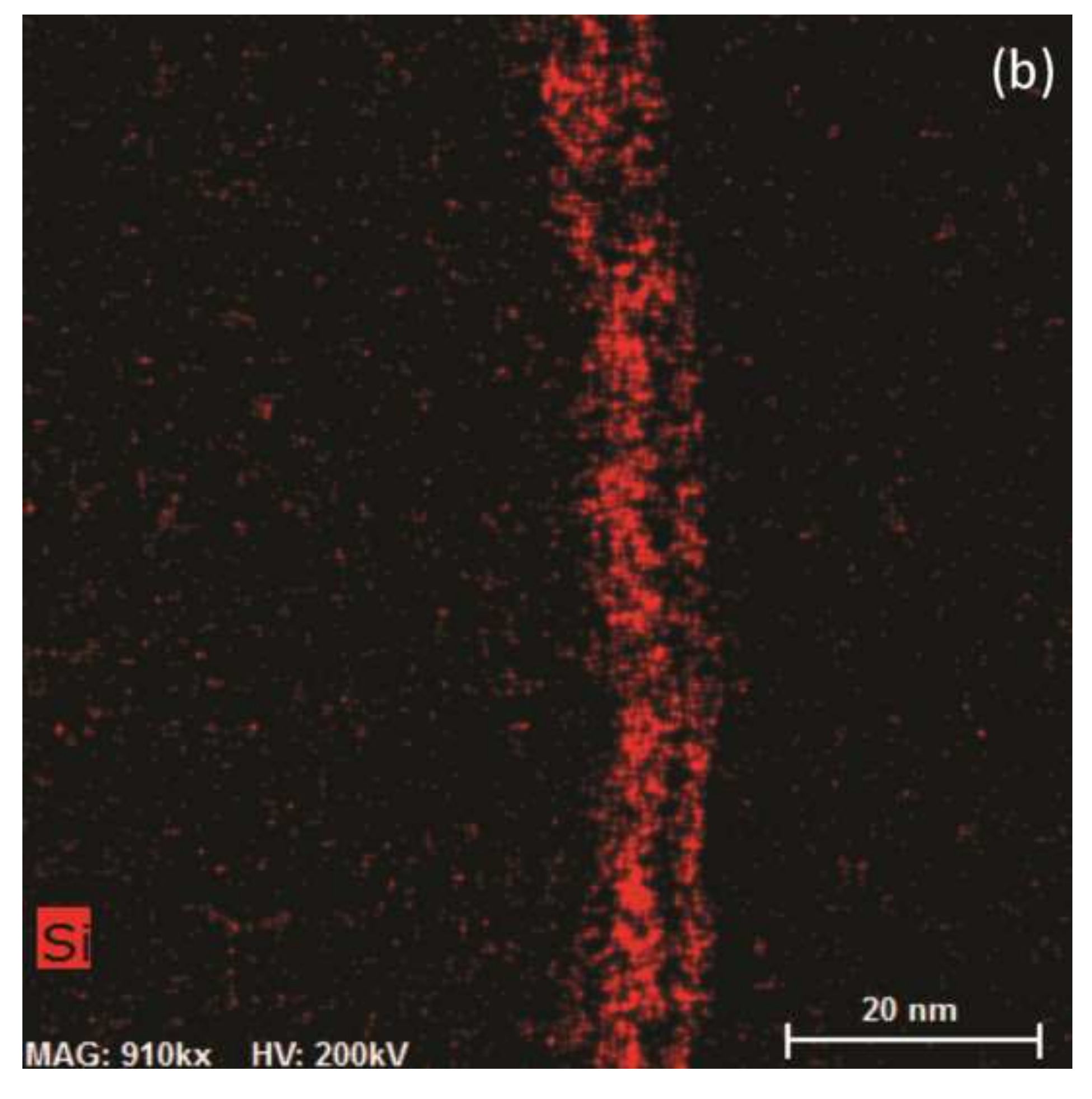

MAG: $910 \mathrm{kx} \quad$ HV: $200 \mathrm{kV}$ 


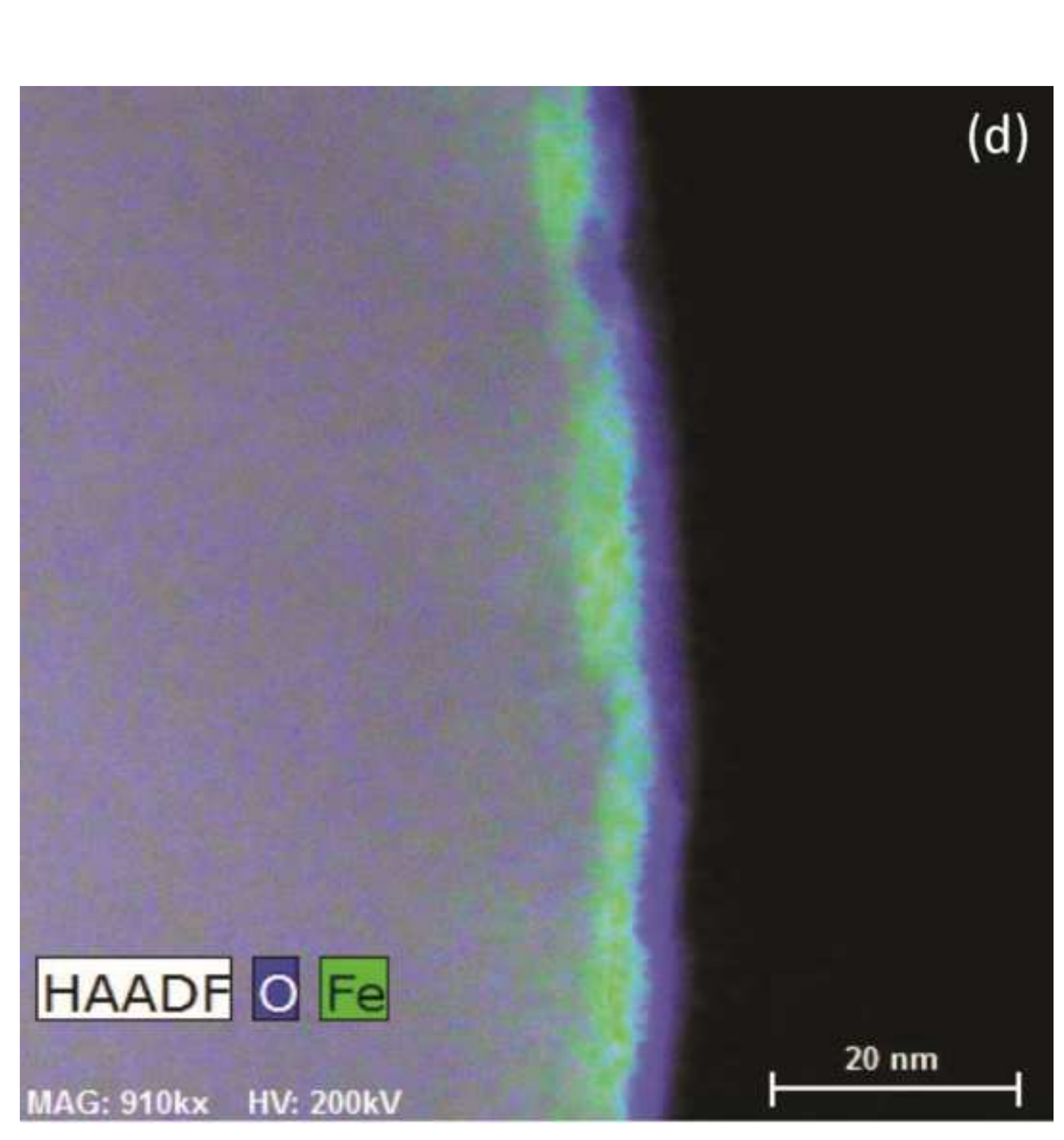

\section{fid.tif

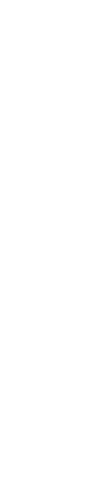

. 


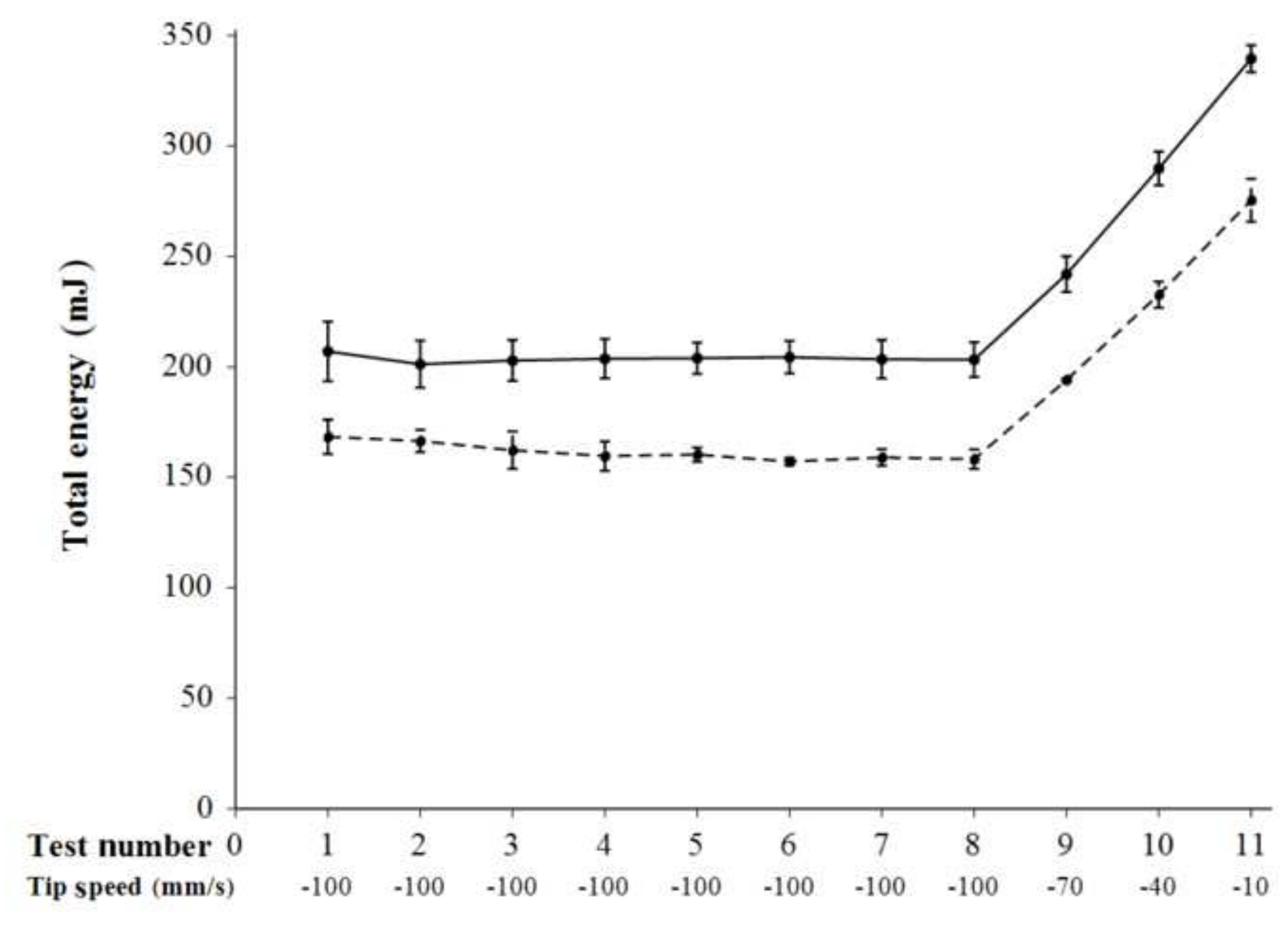




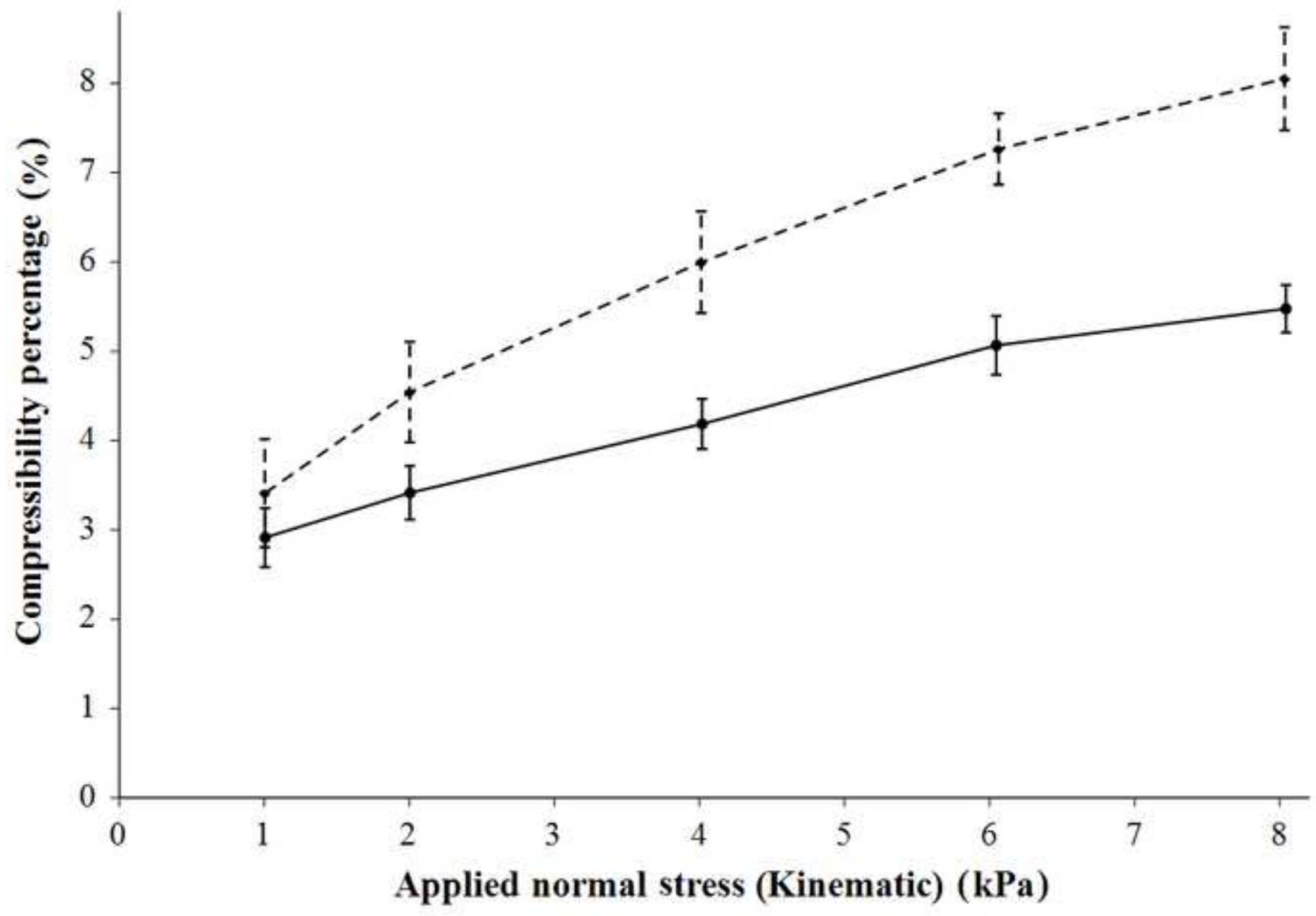




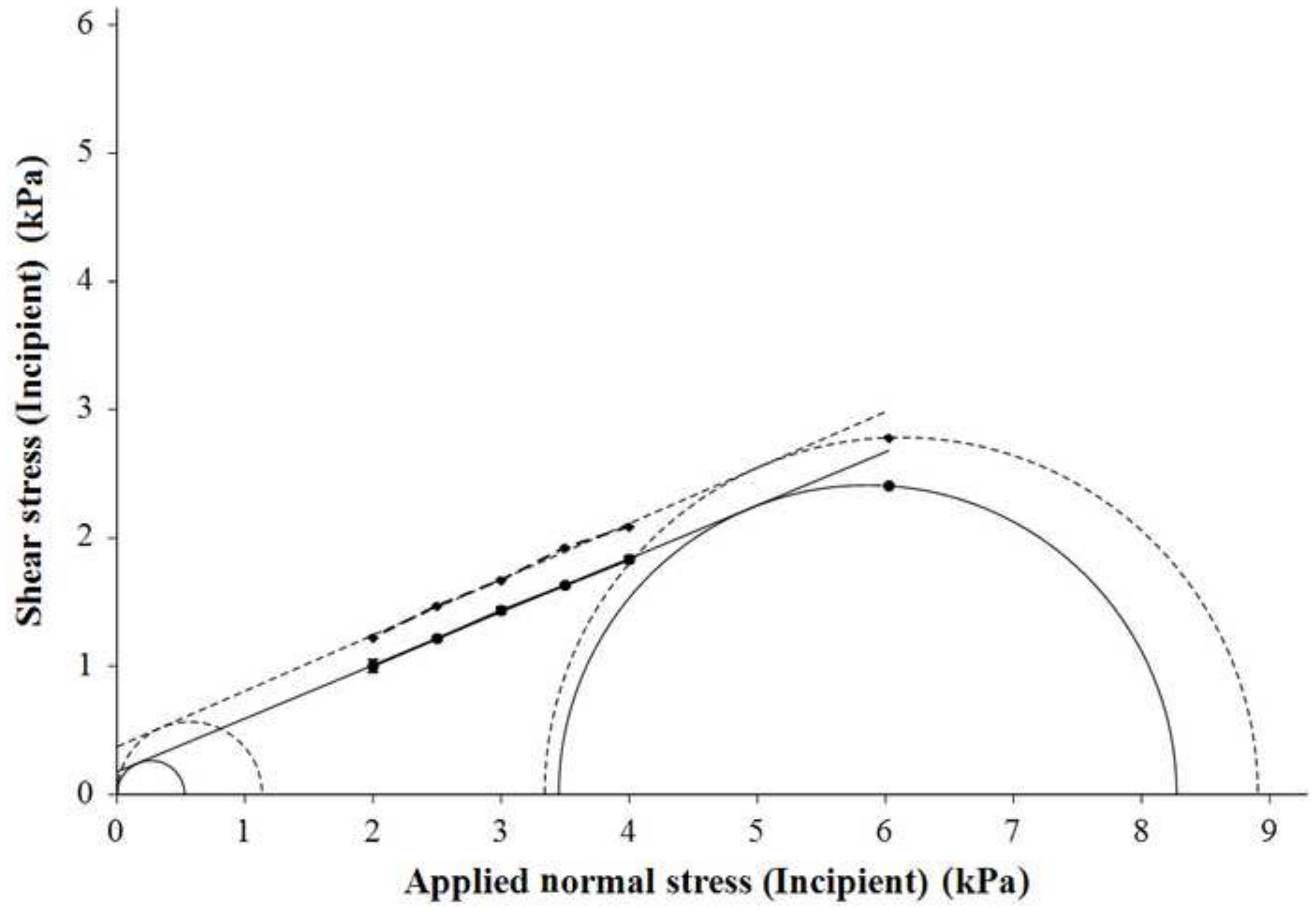




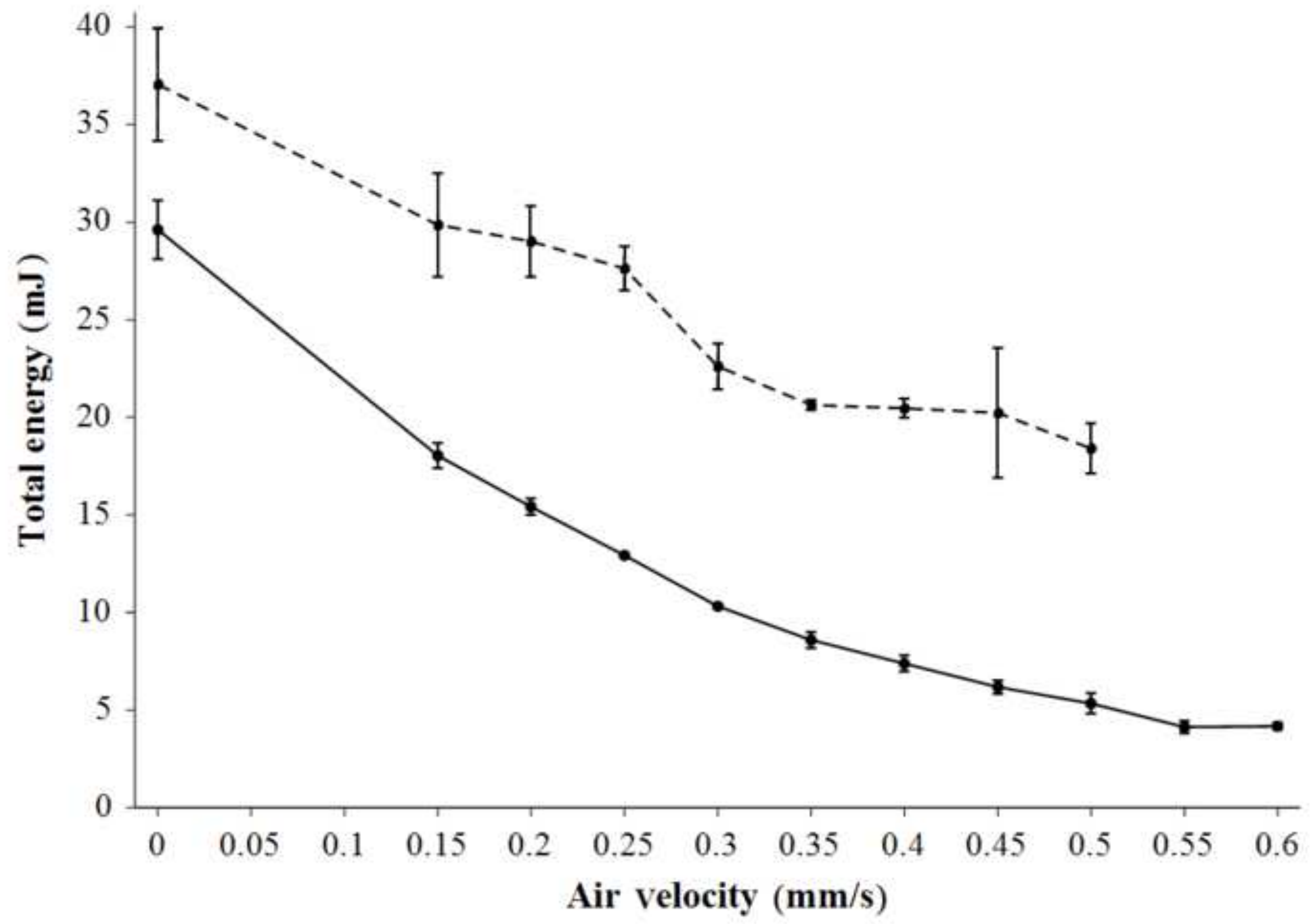




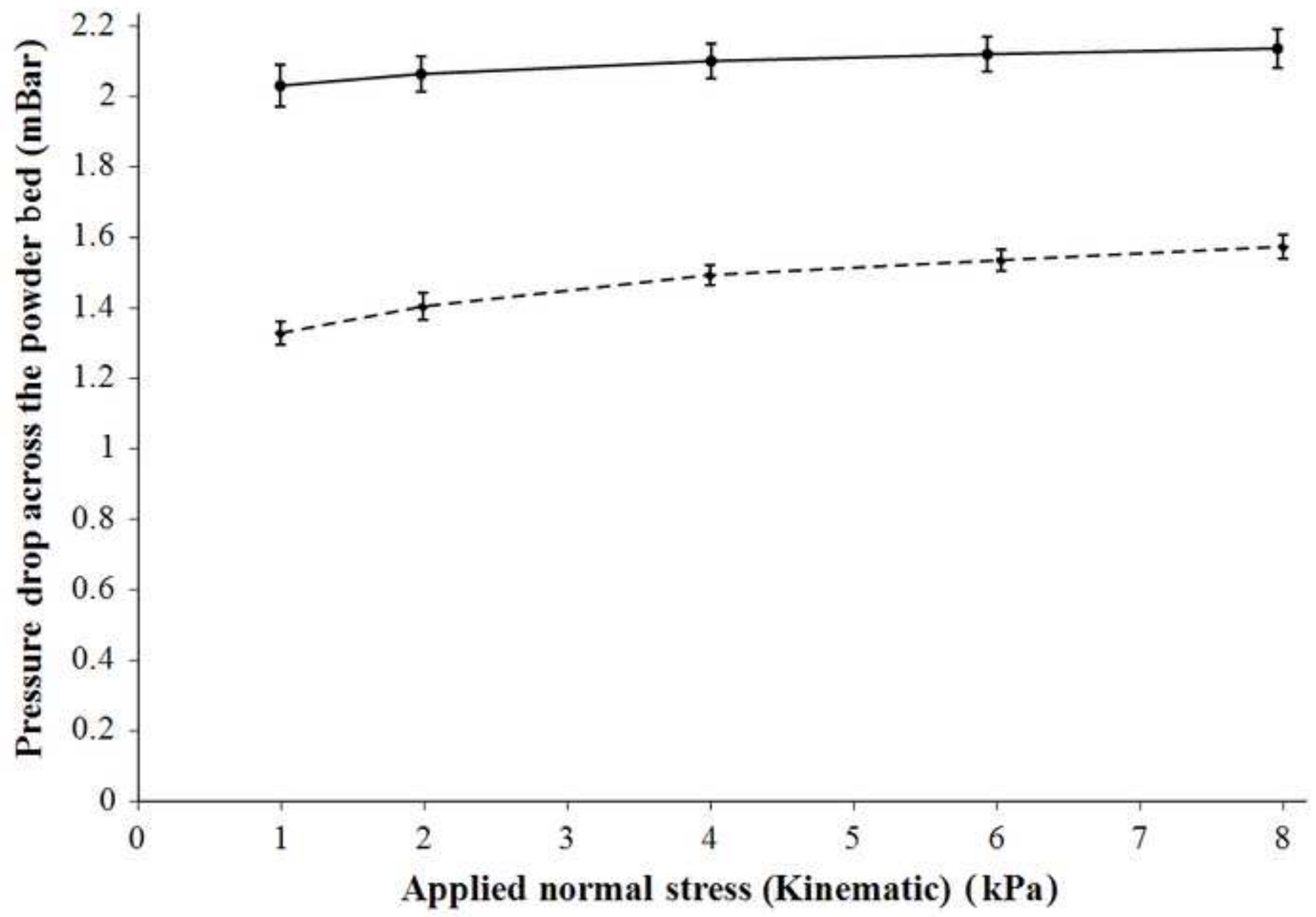

